MARILIA MARTINO DE SANT'ANA

TEMPOS DE REAÇÃO E ATENÇÃO VISUO-ESPACIAL MOBILIZADA VOLUNTARIAMENTE EM ATLETAS E NÃO ATLETAS

Dissertação apresentada ao Programa de PósGraduação em Fisiologia Humana do Instituto de Ciências Biomédicas da Universidade de São Paulo, para obtenção do Título de Mestre em Ciências. 
TEMPOS DE REAÇÃO E ATENÇÃO VISUO-ESPACIAL MOBILIZADA VOLUNTARIAMENTE EM ATLETAS E NÃO ATLETAS

Dissertação apresentada ao Programa de PósGraduação em Fisiologia Humana do Instituto de Ciências Biomédicas da Universidade de São Paulo, para obtenção do Título de Mestre em Ciências.

Área de Concentração: Fisiologia Humana

Orientador: Prof. Dr. Ronald Dennis Paul Kenneth Clive Ranvaud

Versão corrigida. A versão original eletrônica encontra-se disponível tanto na Biblioteca do ICB quanto na Biblioteca Digital de Teses e Dissertações da USP (BDTD). 
DADOS DE CATALOGAÇÃO NA PUBLICAÇÃO (CIP)

Serviço de Biblioteca e Informação Biomédica do

Instituto de Ciências Biomédicas da Universidade de São Paulo

reprodução não autorizada pelo autor

Sant'Ana, Marilia Martino de.

Tempos de reação e atenção visuo-espacial mobilizada voluntariamente em atletas e não atletas / Marilia Martino de Sant'Ana.

-- São Paulo, 2012.

Orientador: Prof. Dr. Ronald Dennis Paul Kenneth Clive Ranvaud.

Dissertação (Mestrado) - Universidade de São Paulo. Instituto de Ciências Biomédicas. Departamento de Fisiologia e Biofísica. Área de concentração: Fisiologia Humana. Linha de pesquisa: Fisiologia do Comportamento.

Versão do título para o inglês: Reaction times and visual-spatial attention mobilized voluntarily in athletes and non-athletes.

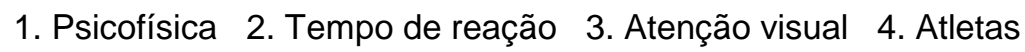
I. Ranvaud, Prof. Dr. Ronald Dennis Paul Kenneth Clive II.

Universidade de São Paulo. Instituto de Ciências Biomédicas.

Programa de Pós-Graduação em Fisiologia Humana III. Título. 
Marilia Martino de Sant'Ana.

Título da Tempos de reação e atenção visuo-espacial mobilizada voluntariamente em atletas e não atletas.

Orientador(a): $\quad$ Prof. Dr. Ronald Dennis Paul Kenneth Clive Ranvaud.

A Comissão Julgadora dos trabalhos de Defesa da Dissertação de Mestrado, em sessão pública realizada a considerou
( ) Aprovado(a)
( ) Reprovado(a)

Examinador(a): Assinatura:

Nome:

Instituição:

Examinador(a): Assinatura:

Nome:

Instituição:

Presidente: Assinatura:

Nome:

Instituição: 


\section{PARECER 976/CEP}

A Comissão de Ética em Pesquisas com Seres Humanos do ICB, na sessão de 25.11.2010, AProvou o projeto intitulado: "Mapeamento no espaço e no tempo da atenção visual em atletas" sob responsabilidade de execução dos autores Prof. Dr. Ronaldo Dennis P.K.C.Ranvaud e a aluna Marilia Martino de Sant' ANa.

Cabe aos pesquisadores executantes elaborar e apresentar a este Comitê, relatórios anuais ( parciais ou final), de acordo com a resolução 196/06 do Conselho Nacional da Saúde, item IX. 2 letra c.

O primeiro relatório deverá ser encaminhado à Secretaria deste CEP em

25.11.2011

Atenciosamente,

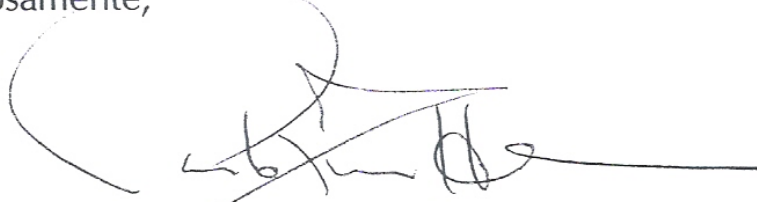

Prof. Dr. Paolo M. A. Zanotto

Coordenador da Comissão de Ética em

Pesquisas com Seres Humanos - ICB/USP 


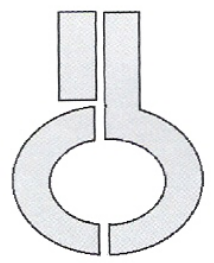

Decl. CEPSH. $056 / 12$

\section{DE CLARA Ç ÃO}

Em adendo ao PARECER 976/CEP, de 25.11.2010, informo que o titulo do Projeto foi alterado para "Tempos de reação e atenção visuo-espacial mobilizada voluntariamente em atletas e não atletas" sob responsabilidade dos autores Ronaldo DenNis P.K.C.RAnVaud e a aluna MARILIA MARTINo DE SANT' ANA, não apresentando restrições quanto às modificações do projeto, que as mesmas não afetam os aspectos éticos da pesquisa.

são Paulo, 28 de novembro de 2012

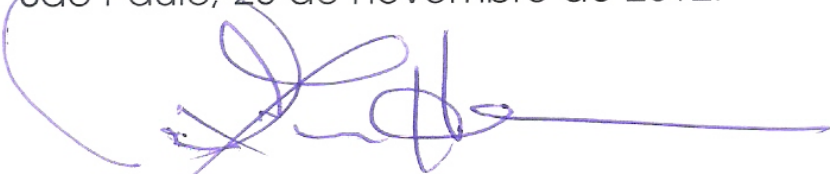

Prof. Dr. Paolo M.A. Zanotto

Coordenador da Comissão de Ética em Pesquisas com Seres Humanos - ICB /USP 


\section{AGRADECIMENTOS}

A minha família, pelo apoio durante todos os momentos. Sem vocês nada disso seria possível.

Aos meus amigos, que são minha segunda família, pelo companheirismo, paciência e ajuda.

Ao professor Ronald Ranvaud, primeiramente por ter permitido meu ingresso no Programa, mas sobretudo pelo aprendizado que me proporcionou durante o longo caminho.

Aos professores Marcos Vinícius Baldo, Edgar Morya e Sérgio Costa, por toda a ajuda e compreensão que demonstraram no Exame de Qualificação e em todos os outros momentos.

Ao Nacional Atlético Clube, pela colaboração em ceder os atletas profissionais de futebol de campo que participaram como voluntários nos experimentos.

Aos estudantes da Universidade de São Paulo, que participaram como voluntários nos experimentos.

A Capes, pelo apoio financeiro. 


\section{RESUMO}

SANT'ANA, M. M. Tempos de reação e atenção visuo-espacial mobilizada voluntariamente em atletas e não atletas. 2013. 73 f. Dissertação (Mestrado em Fisiologia Humana) - Instituto de Ciências Biomédicas, Universidade de São Paulo, São Paulo, 2013.

Existe um crescente interesse em informações científicas quanto ao papel da percepção visual e da atenção visuo-espacial nos esportes. Apesar disso, poucos estudos investigaram os tempos de reação a estímulos visuais apresentados em diferentes posições do campo visual, comparando atletas profissionais e não atletas, na modalidade futebol de campo. O objetivo do presente trabalho foi investigar as diferenças em tarefas de atenção visual mobilizada de maneira voluntária em cinco condições: atenção difusa (sem privilégio para qualquer região do campo visual), atenção manifesta (com o foco atencional direcionado à região foveada), atenção encoberta (focando regiões à direita ou à esquerda do ponto foveado) e atenção dividida (focando simultaneamente duas regiões distintas, à direita e à esquerda do ponto foveado), em atletas de futebol de campo profissionais e em não atletas. A motivação para a realização deste estudo foi que, na prática esportiva, é importante alocar a atenção no campo visual de forma encoberta, direcionando a atenção para uma determinada região do campo visual, longe da fóvea, na ausência de movimentos oculares direcionados àquela região. Torna-se lógico perguntar, portanto, se há diferenças entre atletas e não atletas no desempenho dessas tarefas de orientação encoberta da atenção. Encontrando diferenças, o próximo passo seria verificar se tais diferenças decorrem de traços de personalidade ou do treinamento físico e cognitivo ao qual são submetidos os atletas mais experientes pela prática específica do esporte, ao longo do tempo. O grupo experimental foi formado por atletas de futebol de campo do Nacional Atlético Clube, equipe que disputa campeonatos válidos pela Federação Paulista de Futebol. O grupo controle foi formado por estudantes saudáveis e de idade comparável, matriculados na Universidade de São Paulo. Os dois grupos foram estudados em suas capacidades de orientação voluntária da atenção visuo-espacial, avaliadas por tempos de reação simples a estímulos visuais, nas cinco tarefas de atenção acima especificadas. $\mathrm{O}$ grupo atletas profissionais (AP) apresentou tempos de reação médios mais curtos que o grupo não atletas (NA) em todas as tarefas (significativamente mais curtos nos experimentos de atenção difusa, manifesta, encoberta a direita e dividida). Diferenças nos tempos de reação a estímulos visuais dentro e fora dos focos atencionais não foram significativas $(p>0,31)$ em ambos os grupos, exceto na condição de atenção manifesta $(\mathrm{p}=0,0001)$, mas foram ligeiramente maiores em atletas. Esses achados são diferentes de resultados obtidos em nosso próprio laboratório, com outros grupos de voluntários, que apresentaram benefícios significativos na orientação da atenção visual. Tais discrepâncias provavelmente são devidas a pequenas diferenças nas instruções fornecidas aos voluntários, explicitando prestar atenção em regiões específicas (experimentos anteriores), ou simplesmente dizendo que naquelas regiões haveria maior densidade de estímulos (no presente trabalho). Importante salientar que na literatura existem resultados contraditórios na comparação entre atletas e não atletas em tarefas atencionais e de cronometria mental, possivelmente também decorrentes de detalhes nas condições experimentais. Concluímos que experimentos que adotem protocolos semelhantes ao do presente trabalho devem ser executados com muito cuidado, sendo especialmente importante padronizar rigorosamente as instruções fornecidas aos voluntários.

Palavras-chave: Psicofísica. Tempo de reação. Atenção visual. Atletas 


\begin{abstract}
SANT'ANA. M. M. Reaction time and visuospatial attention mobilized voluntary in athletes and non-athletes. 2013. 73 p. Masters thesis (Human Physiology) - Instituto de Ciências Biomédicas, Universidade de São Paulo, São Paulo, 2013.
\end{abstract}

There is growing interest in scientific information about the role of visual perception and visuospatial attention in sports. Nevertheless, few studies have investigated the reaction times to visual stimuli presented in different positions in the visual field, comparing professional soccer athletes and non-athletes. The objective of this study was to investigate differences in visual voluntary attention tasks under conditions of diffuse (without privilege for any region of the visual field), manifest (with attentional focus directed to the foveal region), covert (focusing attention in regions to the right or left of the foveal spot) and divided attention (focusing attention simultaneously in two distinct regions, to the right and left of the foveal spot) in professional soccer athletes and non-athletes. The motivation for this study was that in sports it is important to allocate attention covertly in the visual field, directing attention to a particular region of the visual field, away from the fovea, in the absence of eye movements directed to that region. It is logical to ask, therefore, whether there are differences between athletes and non-athletes in these tasks of covert attention. Finding differences, the next step would be verify if these differences are related to personality traits or cognitive and physical training to which the more experienced athletes are specifically submitted in practicing sport over time. The experimental group consisted of professional athletes from the Nacional Atlético Clube. The control group consisted of healthy age-matched students, enrolled in the University of São Paulo. Both groups were studied in their ability to guide voluntary visuospatial attention, assessed by simple reaction times to visual stimuli in the five attention tasks described above. Professional athletes (PA) showed shorter reaction times than nonathletes (NA) in all tasks (significantly shorter in diffuse, manifest, cover to the right and divided attention tasks). Differences in reaction times to visual stimuli inside and outside the attentional focus were not significant $(\mathrm{p}>0.31)$ in both groups, except for the manifest attention condition $(\mathrm{p}=0.0001)$, but were slightly higher in athletes. These findings differ from results obtained in our own laboratory, with other volunteer groups, which showed significant benefits in orienting visual attention, probably due to small differences in the instructions given to volunteers, asking them to explicit pay attention to specific regions (in the previous experiments) or simply saying that specific regions had higher density of stimuli (in this work) Important to note that in the literature there are contradictory results comparing athletes and non-athletes in attentional tasks and mental chronometry. Such discrepancies may be due to details in the experimental conditions. We conclude that experiments that adopt protocols that are similar to the one used in the present study, must be performed very carefully, being especially important to rigorously standardize the instructions provided to volunteers.

Keywords: Psychophysics. Reaction time. Visual attention. Athletes. 


\section{LISTA DE ILUSTRAÇÕES}

Figura 1 - Diagrama de formação de imagens no olho.........................................................14

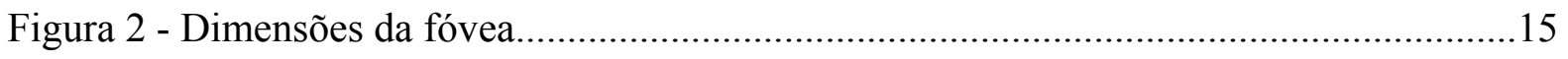

Figura 3 - Distribuição da densidade de fotorreceptores (cones e bastonetes) na retina...........16

Figura 4 - Descrição dos movimentos oculares durante uma fixação......................................17

Figura 5 - Campos visuais do olho esquerdo e direito...........................................................18

Figura 6 - Protocolo experimental adotado por Herman Von Helmholtz.................................22

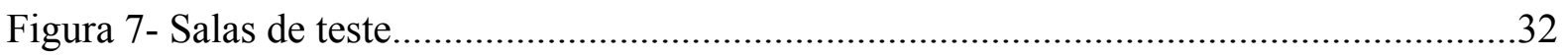

Figura 8 - Situação experimental, com os voluntários em posição.........................................33

Figura 9- Componentes de montagem do eye tracker.......................................................33

Figura 10 - Monitoramento ocular, realizado pelo eye tracker construído no laboratório.......34

Figura 11 - Registro das tentativas válidas e inválidas pelo Experimental Eye.......................34

Figura 12 - Registro das posições oculares mostrado pelo Experimental Eye.........................35

Figura 13 - Joystick utilizado pelos voluntários durante as tarefas.........................................36

Figura 14 - Diagrama temporal da apresentação dos estímulos nos experimento.....................37

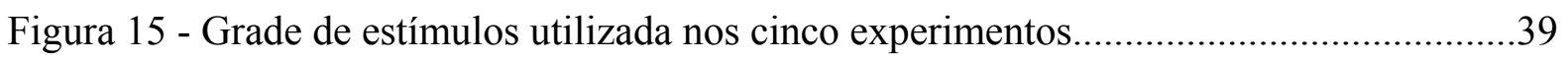

Quadro 1 - Tempos de reação médios do grupo atletas profissionais (AP) e não atletas (NA) em todas as situações experimentais (experimentos de I a V)..............................................54

Figura 16 - Tempos de reação médios (TR Médio) aos estímulos visuais que apareceram dentro e fora da moldura, em cada condição experimental (experimentos II a V), para o grupo

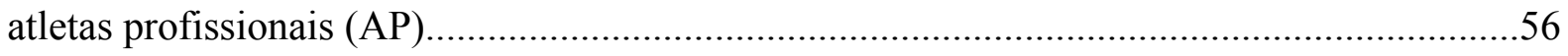

Figura 17 - Tempos de reação médios (TR Médio) aos estímulos visuais que apareceram dentro e fora da moldura, em cada condição experimental (experimentos II a V), para o grupo não atletas (NA). .56 


\section{LISTA DE GRÁFICOS}

Gráfico 1 - Comparação entre os tempos de reação médios do grupo atletas profissionais (AP) e do grupo não atletas (NA) no Experimento I (Atenção Difusa).

Gráfico 2 - Comparação entre os tempos de reação médios do grupo atletas profissionais (AP) e do grupo não atletas (NA) no Experimento II (Atenção Manifesta).

Gráfico 3 - Comparação entre os tempos de reação médios do grupo atletas profissionais (AP) aos estímulos que ocorreram nas condições dentro e fora da moldura no Experimento II (Atenção Manifesta).

Gráfico 4 - Comparação entre os tempos de reação médios do grupo não atletas (NA) aos estímulos que ocorreram nas condições dentro e fora da moldura no Experimento II (Atenção Manifesta).

Gráfico 5 - Comparação entre os tempos de reação médios do grupo atletas (AP) e não atletas (NA) aos estímulos que ocorreram nas condições dentro e fora da moldura no Experimento II (Atenção Manifesta).

Gráfico 6 - Comparação entre os tempos de reação médios do grupo atletas profissionais (AP) e do grupo não atletas (NA) no Experimento III (Atenção Encoberta a Esquerda)......

Gráfico 7 - Comparação entre os tempos de reação médios do grupo atletas profissionais (AP) aos estímulos que ocorreram nas condições dentro e fora da moldura no Experimento III (Atenção Encoberta a Esquerda).

Gráfico 8 - Comparação entre os tempos de reação médios do grupo não atletas (NA) aos estímulos que ocorreram nas condições dentro e fora da moldura no Experimento II (Atenção Encoberta a Esquerda).

Gráfico 9 - Comparação entre os tempos de reação médios do grupo atletas (AP) e não atletas (NA) aos estímulos que ocorreram nas condições dentro e fora da moldura no Experimento II (Atenção Encoberta a Esquerda).

Gráfico 10 - Comparação entre os tempos de reação médios do grupo atletas profissionais (AP) e do grupo não atletas (NA) no Experimento IV (Atenção Encoberta a Direita)...... .48

Gráfico 11 - Comparação entre os tempos de reação médios do grupo atletas profissionais (AP) aos estímulos que ocorreram nas condições dentro e fora da moldura no Experimento IV (Atenção Encoberta a Direita).

Gráfico 12 - Comparação entre os tempos de reação médios do grupo não atletas (NA) aos estímulos que ocorreram nas condições dentro e fora da moldura no Experimento IV (Atenção Encoberta a Direita). 
Gráfico 13 - Comparação entre os tempos de reação médios do grupo atletas (AP) e não atletas (NA) aos estímulos que ocorreram nas condições dentro e fora da moldura no Experimento IV (Atenção Encoberta a Direita)

Gráfico 14 - Comparação entre os tempos de reação médios do grupo atletas profissionais (AP) e do grupo não atletas (NA) no Experimento V (Atenção Dividia).

Gráfico 15 - Comparação entre os tempos de reação médios do grupo atletas profissionais (AP) aos estímulos que ocorreram nas condições fora da moldura, dentro da moldura 1 (a esquerda) e dentro da moldura 2 (a direita) no Experimento V (Atenção Dividida). .52

Gráfico 16 - Comparação entre os tempos de reação médios do grupo não atletas (NA) aos estímulos que ocorreram nas condições fora da moldura e dentro da moldura 1 (a esquerda) e 2 (a direita) no Experimento V (Atenção Dividida). .52

Gráfico 17: Comparação entre os tempos de reação médios do grupo atletas (AP) e não atletas (NA) aos estímulos que ocorreram nas condições fora da moldura, dentro da moldura 1 (à direita) e dentro da moldura 2 (à esquerda) no Experimento V (Atenção Dividida). .53

Gráfico 18: Comparação entre os tempos de reação médios dos grupos atletas profissionais (AP) e não atletas (NA) nas cinco condições experimentais. 


\section{SUMÁRIO}

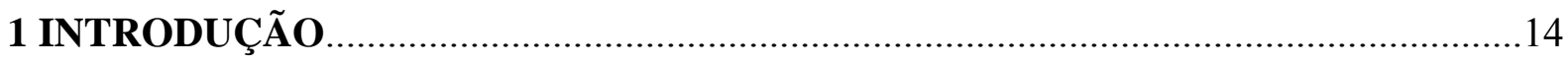

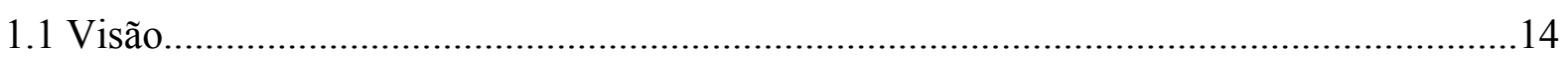

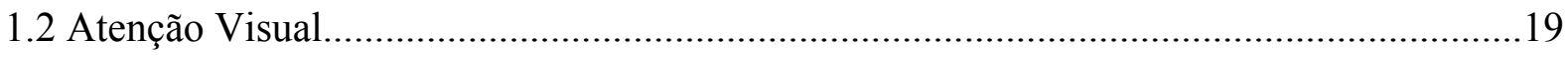

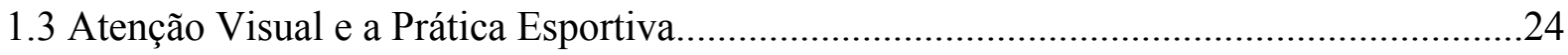

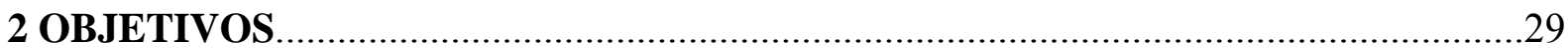

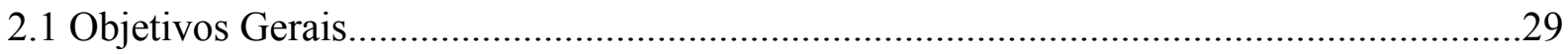

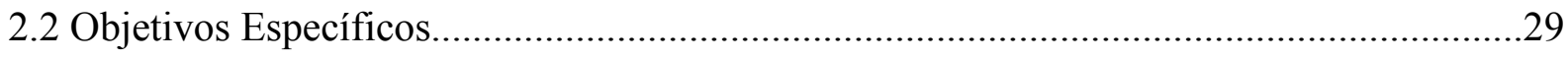

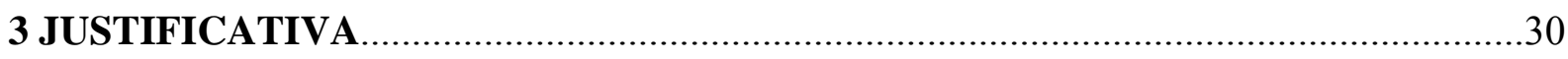

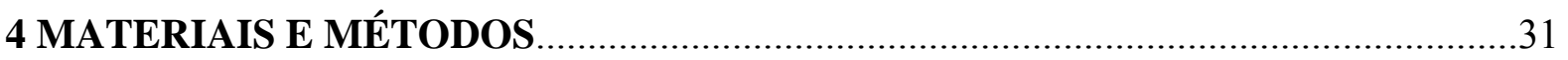

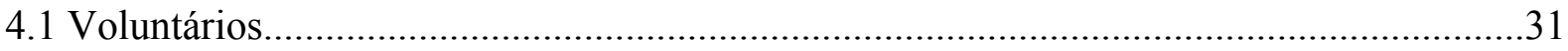

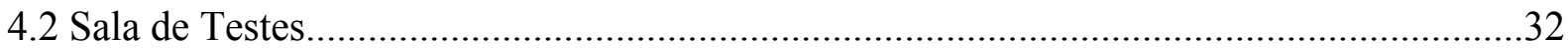

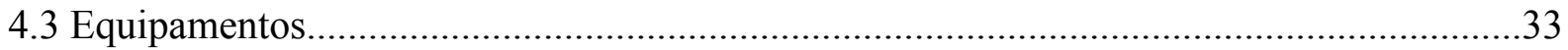

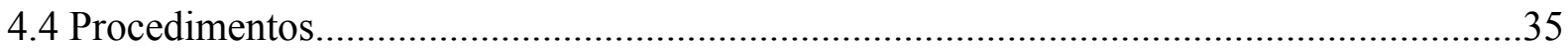

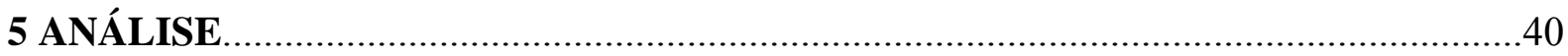

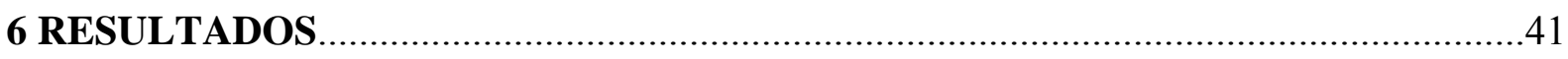

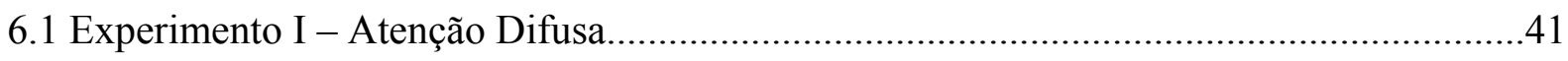

6.1.1 Atletas Profissionais vs Não Atletas (Tempos de Reação Médios)..................................41

6.2 Experimento II - Atenção Manifesta....................................................................................42

6.2.1 Atletas Profissionais vs Não Atletas (Tempos de Reação Médios)..................................42

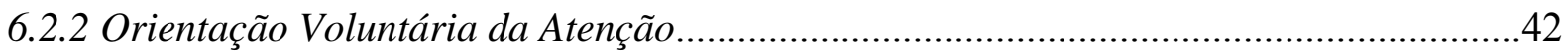

6.3 Experimento III - Atenção Encoberta a Esquerda.............................................................4

6.3.1 Atletas Profissionais vs Não Atletas (Tempos de Reação Médios)...................................44

6.3.2 Orientação Voluntária da Atenção...............................................................................45

6.4 Experimento IV - Atenção Encoberta a Direita.................................................................47

6.4.1 Atletas Profissionais vs Não Atletas (Tempos de Reação Médios)...................................47

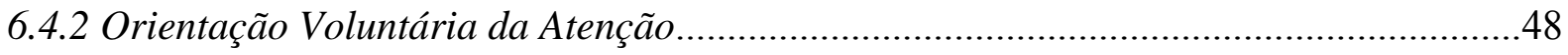

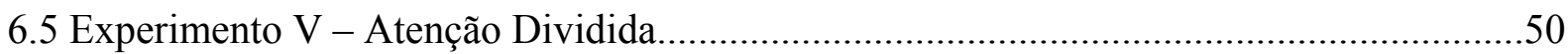

6.5.1 Atletas Profissionais vs Não Atletas (Tempos de Reação Médios).................................50

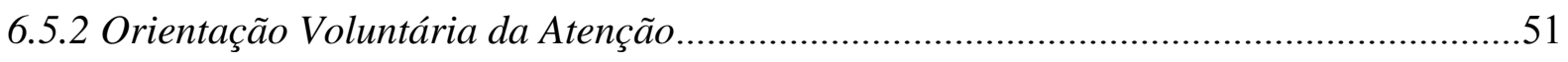

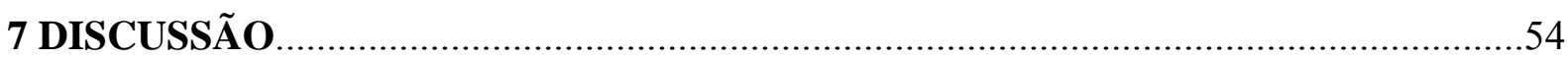

7.1 Atletas Profissionais vs Não Atletas (Tempos de Reação Médios).....................................54

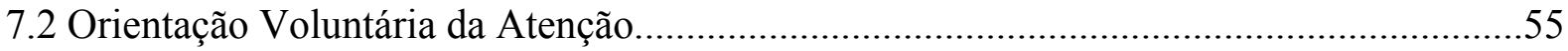


8 CONCLUSÃO .60

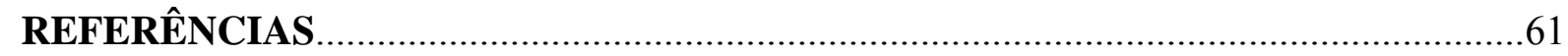

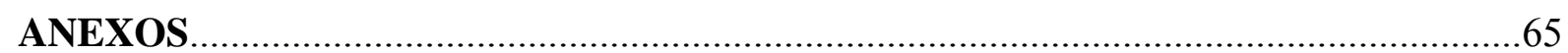

ANEXO A - Termo de Consentimento Livre e Esclarecido..............................................65

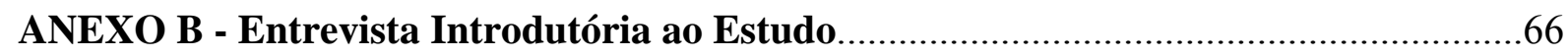

ANEXO C - Inventário de Dominância Lateral de Edimburgo.......................................67

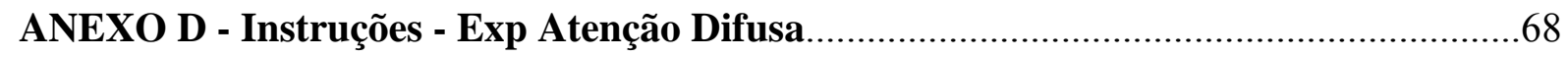

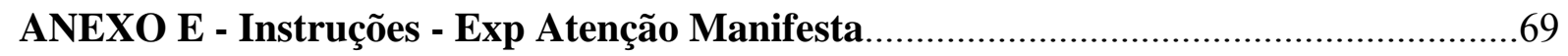

ANEXO F - Instruções - Exp Atenção Encoberta E................................................... 70

ANEXO G - Instruções - Exp Atenção Encoberta D..................................................

ANEXO H - Instruções - Exp Atenção Dividida.......................................................

ANEXO I - Instruções - Intervalos e Pausas entre os Blocos...........................................73 


\section{INTRODUÇÃO}

1.1 Visão

A visão é um dos sentidos mais importantes nos seres humanos, e junto com a audição, é a base da maior parte da comunicação humana (BERNE; LEVI, 2006). A informação visual domina nossas percepções e molda a maneira como pensamos (GAZZANIGA; IVRY; MANGUN, 2006).

A visão nos torna capazes de perceber a informação à distância, encarregando-se do que é denominado deteç̧ão remota ou percepção exteroceptiva, pois não necessitamos estar em contato imediato com um estímulo para processá-lo. As vantagens para o emprego da situação remota são óbvias: um organismo certamente pode melhor evitar um predador ao detectá-lo à distância. Seria provavelmente muito tarde para escapar de um tubarão se seus dentes já tivessem perfurado nossa pele (GAZZANIGA; IVRY; MANGUN, 2006).

A informação visual está contida na luz refletida e espalhada dos objetos. A visão depende de detectores sensoriais que respondem à luz que incide na retina. À medida que a luz passa através da córnea e da lente do olho, a imagem é formada (Figura 1), se projetando para a superfície posterior do olho, onde se situa a retina (GAZZANIGA; IVRY; MANGUN, 2006).

Figura 1 - Diagrama de formação de imagens no olho

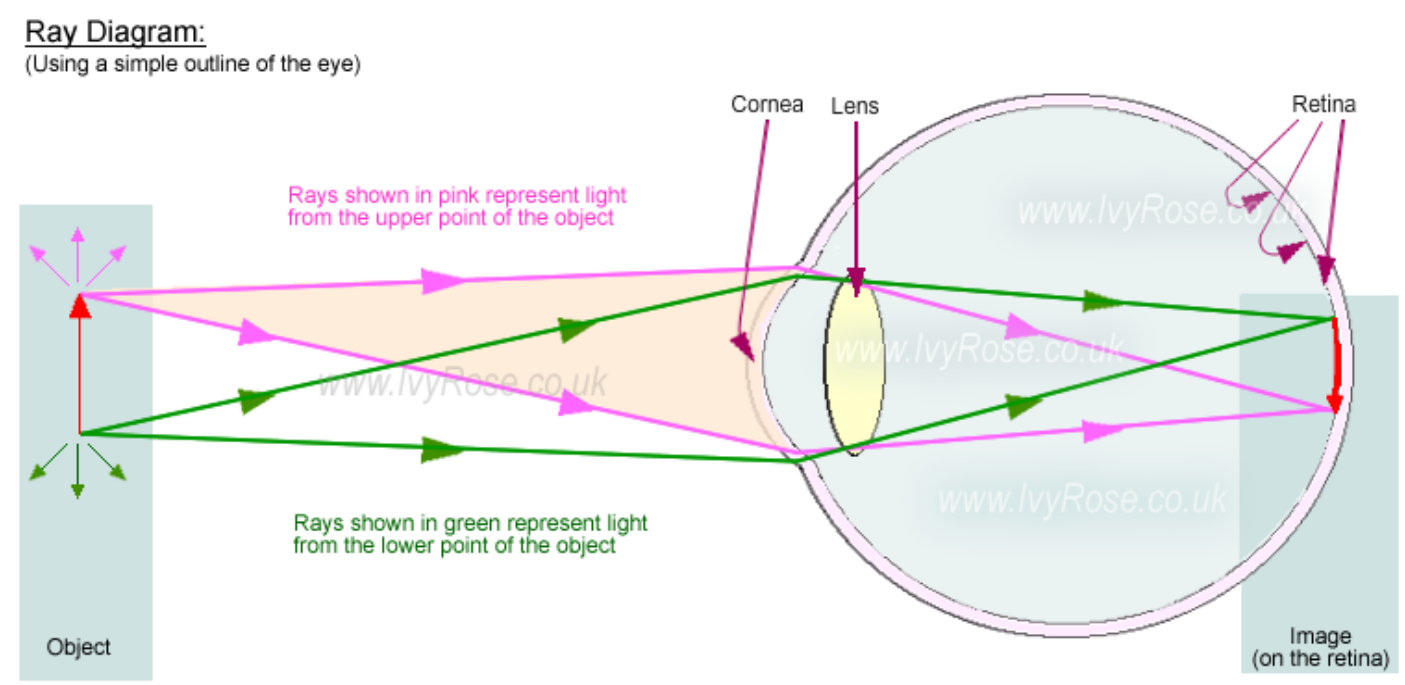

Fonte: Ivyrose holistic (2012 ). 
Toda a percepção envolve sinais no Sistema Nervoso, como resultado de estímulos físicos que atingem órgãos sensorias. A percepção não é o recebimento passivo destes sinais pelos receptores: ela pode ser moldada pelo aprendizado, memória e expectativa (GAZZANIGA; IVRY; MANGUN, 2006).

A camada mais profunda da retina é composta de milhões de fotorreceptores, cada um contendo moléculas sensíveis à luz, ou fotopigmentos. Quando expostos à luz, os fotopigmentos tornam-se instáveis, alterando sua conformação. Sua decomposição altera o fluxo de corrente elétrica ao redor do fotorreceptor. Essa mudança induzida pela luz dispara potenciais de ação nos neurônios ao longo dessa via. Assim, os fotorreceptores traduzem um estímulo externo (luz) em sinal interno neural: a detecção desse estímulo (GAZZANIGA; IVRY; MANGUN, 2006).

Existem dois tipos de fotorreceptores na retina: os cones e os bastonetes. Os bastonetes são sensíveis à baixos níveis de estimulação e são mais úteis à noite, quando a energia luminosa está reduzida. Os cones precisam de níveis mais intensos de luz, e são mais ativos durante a visão diurna. Os cones também são essenciais para a visão de cores (GAZZANIGA; IVRY; MANGUN, 2006).

Figura 2 - Dimensões da fóvea

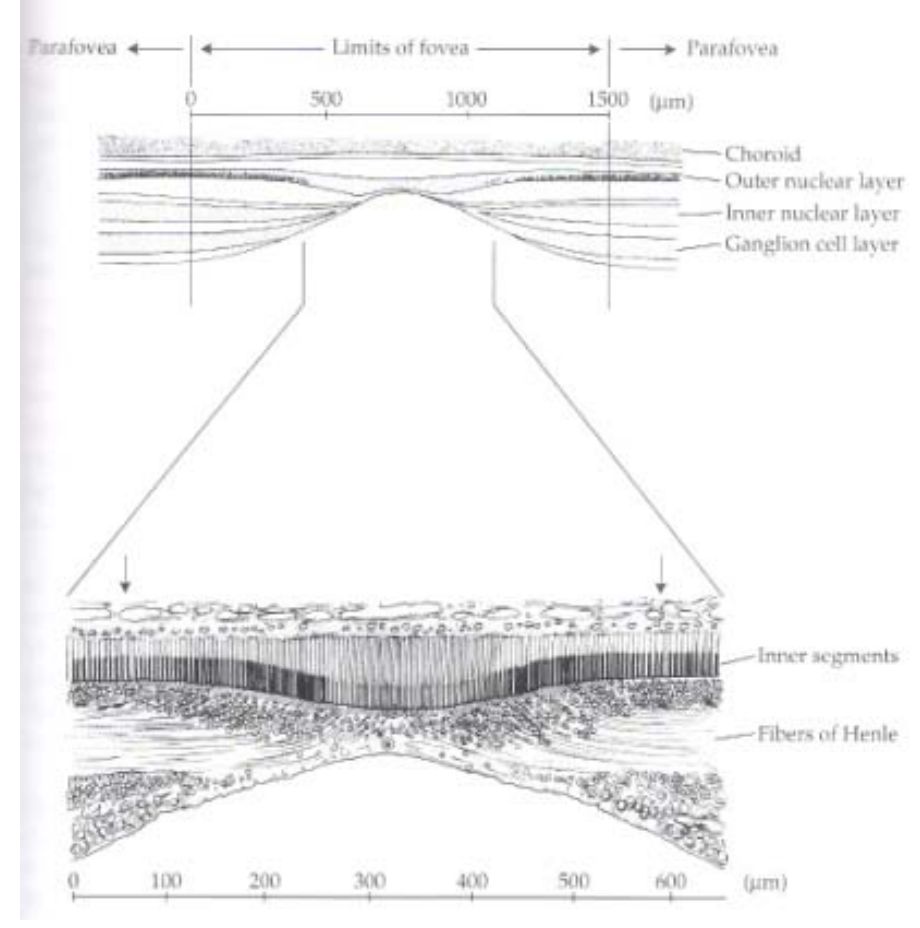

Fonte: Oyster, 1999. 
Os cones e bastonetes não estão distribuídos igualmente na retina. Os cones estão densamente dispostos próximos ao centro da retina, em uma região denominada fóvea, uma pequena depressão, de 1,5 mm (Figura 2), que permite que os detalhes finos do estímulo visual sejam percebidos claramente (WRIGHT; LAWRENCE, 2008). Poucos cones estão nas regiões mais excêntricas da retina. Os bastonetes, por sua vez, estão distribuídos prioritariamente nas regiões periféricas (Figura 3).

Figura 3 - Distribuição da densidade de fotorreceptores (cones e bastonetes) na retina

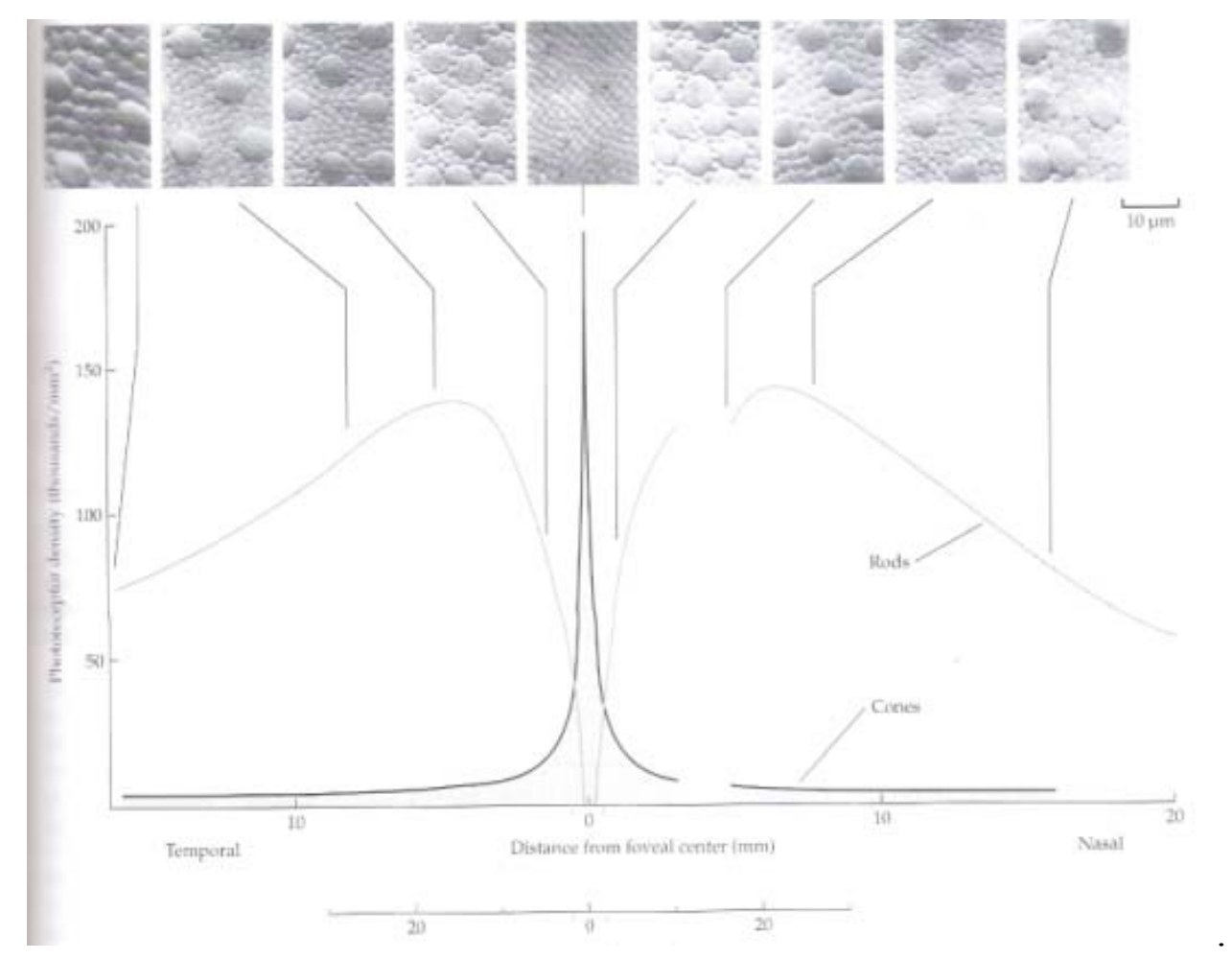

Fonte: Oyster, 1999.

Enquanto a porção central da retina (fóvea) possibilita a análise visual com alta acuidade, a região periférica da retina é mais sensível ao movimento, mudanças no brilho e ao aparecimento abrupto de novos objetos. Essa organização da retina é eficiente, porque permite uma alta acuidade nos estímulos foveais enquanto permanecemos vigilantes e sensíveis aos eventos e estímulos que possam ocorrer na periferia visual (WRIGHT; LAWRENCE, 2008).

A retina humana tem uma pequena região, no centro da fóvea, onde os fotorreceptores do tipo cones são mais finos e dispostos densamente. A região em que a densidade de cones está acima de $50 \%$ da densidade máxima tem pouco menos de 1 grau de diâmetro no campo visual, e nos fornece a melhor resolução de detalhes finos (OYSTER, 1999). Para se ter uma 
idéia do que isso significa, podemos mencionar que a lua cheia tem um diâmetro aparente de aproximadamente 0,5 graus, e que o dedo mínimo, visto quando o braço estiver estendido, subtende um ângulo visual de aproximadamente 1 grau.

A posição dos olhos na órbita está sempre mudando, estando-se consciente dessas mudanças ou não. Nossos olhos estão constantemente se movimentando, mesmo quando olhamos fixamente para algum objeto muito pequeno. Os movimentos durante fixações são muito discretos e requerem um sistema extremamente sensível para que seja possível detectálos. A figura 4 mostra que existem três componentes de movimentos: um tremor de alta frequência, denominado micronistagmo, que se sobrepõe a um deslocamento de baixa velocidade (deriva), interrompido, de vez em quando (cerca de uma vez por segundo) por um rápido movimento de correção (microsacada). Nestas condições, que caracterizam-se como fixações, a imagem na retina está constantemente mudando de lugar no padrão dos movimentos dos olhos (OYSTER, 1999).

Figura 4 - Movimentos oculares durante uma fixação.

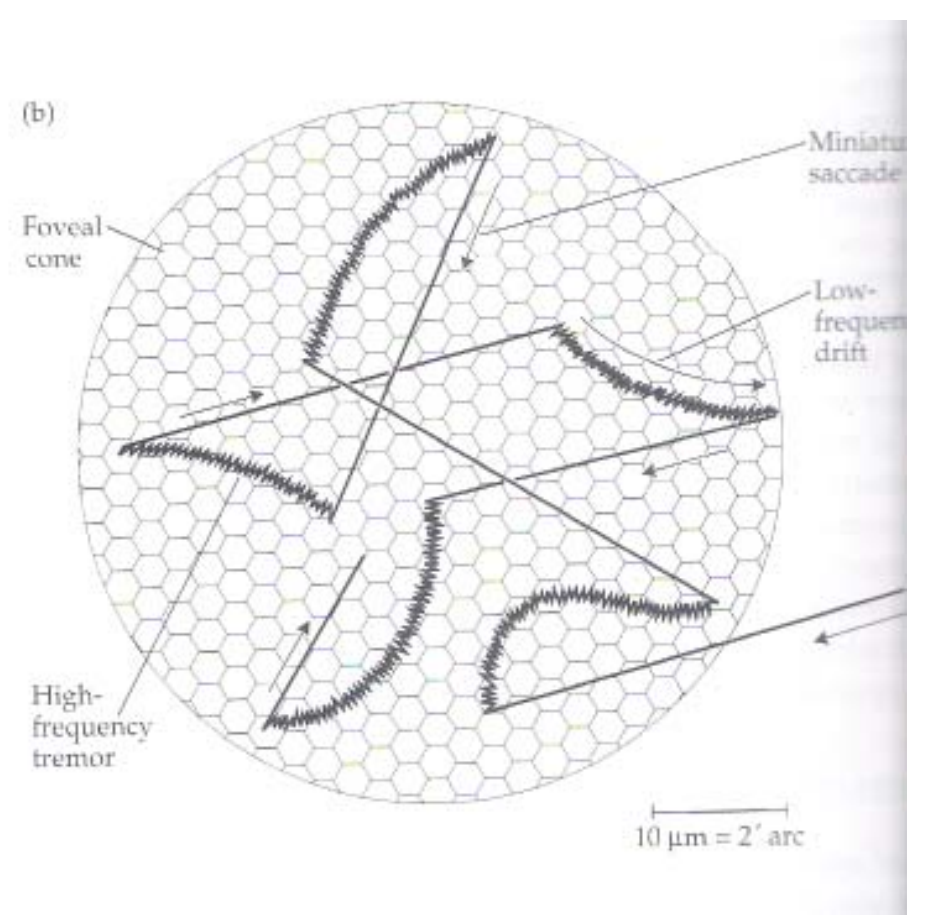

Fonte: Oyster, 1999.

$\mathrm{Na}$ retina é realizado um importante processamento da informação visual. A informação liberada pelos fotorreceptores é processada pelas células horizontais, amácrinas e bipolares, e dessas segue para as células ganglionares. No processamento, dentro das camadas da retina, ocorre extensa convergência da informação. Evidência disso é o fato de estimar-se 
que existam 260 milhões de fotorreceptores e apenas 2 milhões de células ganglionares, a única fonte de eferência do olho. Esse processamento retiniano ameniza a tarefa dos centros visuais de ordem superior na tarefa de recuperar detalhes importantes do mundo visual (GAZZANIGA; IVRY; MANGUN, 2006).

Os axônios das células ganglionares formam um feixe, o nervo óptico, através do qual a informação visual é transmitida ao sistema nervoso central. Antes de entrar no encéfalo, cada nervo óptico se divide em duas partes. O ramo temporal (ou lateral) segue pelo mesmo hemisfério. O ramo nasal (ou medial) cruza a linha média e projeta-se para o hemisfério oposto. Este cruzamento ocorre no quiasma óptico (GAZZANIGA; IVRY; MANGUN, 2006).

Figura 5 - Campos visuais do olho esquerdo e direito

Fonte: Portal São Francisco (2012).

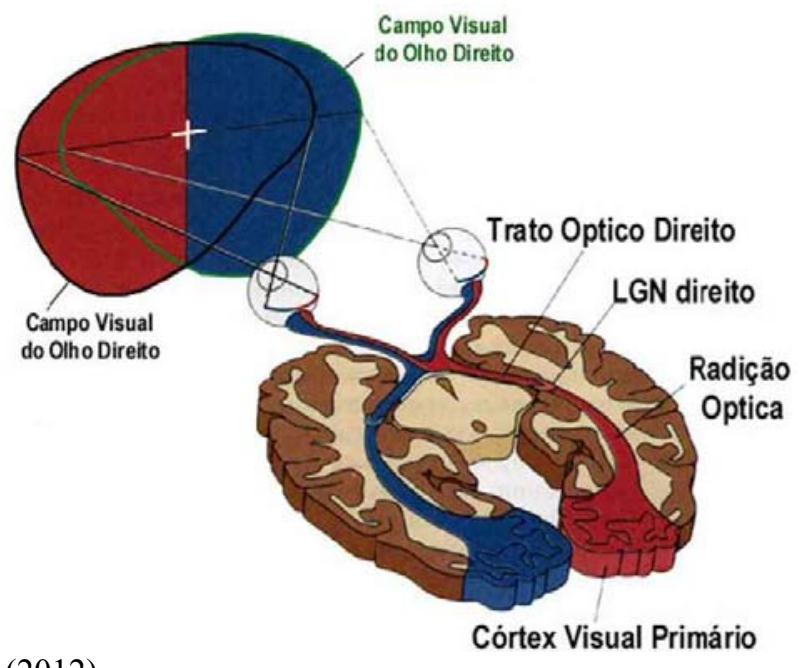

De acordo com as características ópticas do olho, o cruzamento das fibras nasais assegura que a informação visual de cada lado do campo visual seja projetada para as estruturas encefálicas contralaterais: devido à curvatura da retina, a metade temporal da retina direita é estimulada pelos objetos do campo visual esquerdo, e da mesma forma, a hemiretina nasal do olho esquerdo é estimulada pela mesma região do espaço externo (Figura 5). Como as fibras de cada hemiretina nasal se cruzam, toda a informação visual do campo visual esquerdo se projeta ao córtex visual primário do hemisfério direito e a informação visual do campo visual direito é projetada ao córtex visual primário do hemisfério esquerdo (GAZZANIGA; IVRY; MANGUN, 2006; POSNER; RAICHEL, 1994). 


\subsection{Atenção Visual}

Não percebemos tudo que ilumina nossas retinas, que soa em nossas cócleas, acaricia nossa pele e sopra em nossas narinas. O que escolhemos prestar atenção e o que de fato prende nossa atenção pode dominar nossa experiência e a interação com o ambiente ao nosso redor (GAZZANIGA; IVRY; MANGUN, 2006).

A atenção é um mecanismo cerebral cognitivo que possibilita o processamento de informações, pensamentos ou ações relevantes, enquanto ignoram-se outros, irrelevantes ou dispersivos, e pode ser operada sem o ajuste declarado de estruturas sensoriais. Como exemplo, é possível dirigir a atenção visual para locais ou objetos no ambiente cujas imagens caem na periferia da retina, sem que ocorram movimentos dos olhos (GAZZANIGA; IVRY; MANGUN, 2006).

A atenção visual é um mecanismo nervoso pelo qual recursos de processamento visual de estímulos luminosos do ambiente são direcionados preferencialmente, de forma voluntária ou espontânea, privilegiando um determinado local ou objeto em detrimento de outros, vividos simultaneamente. Envolve tanto processos voluntários, independentes dos estímulos luminosos do ambiente, denominados top-down (de cima para baixo), quanto reflexos, decorrentes do processamento de estímulos luminosos do ambiente (desencadeados por potenciais de ação gerados em fotorreceptores retinianos) ou mecanismos guiados por estímulos, denominados bottom-up (de baixo para cima) (GAZZANIGA; IVRY; MANGUN, 2006; POSNER; RAICHEL, 1994).

Processos bottom-up se referem a processamentos que estão sendo realizados automaticamente ou reflexivamente pela estimulação, mesmo se o indivíduo é instruído a manter-se passivo diante do evento. O processo top-dow é gerado internamente pelo próprio indivíduo, geralmente com sua atenção ativa, de maneira voluntária (POSNER; RAICHEL, 1997). Esses processos estão em competição dinâmica pelo controle do foco momentâneo da atenção, e seus efeitos influenciam a forma na qual a informação é processada no cérebro. Redes cerebrais difusas interagem para permitir que nos ocupemos com eventos relevantes e ignoremos os irrelevantes (CARREIRO; FERREIRA; MACHADO-PINHEIRO, 2009; GAZZANIGA; IVRY; MANGUN, 2006).

Baseando-se nestes parâmetros, a atenção pode ser dividida em duas amplas categorias: atenção voluntária, ou atenção endógena, e atenção reflexa (automática), ou atenção exógena. 
A atenção voluntária se refere à nossa habilidade ou intencionalidade em prestar atenção em algum objeto, local ou evento, enquanto a atenção reflexa (ou automática) descreve o fenômeno no qual algum evento sensorial capta nossa atenção. Estas duas formas de orientar a atenção diferem em suas propriedades temporais e em seus mecanismos neurais (GAZZANIGA; IVRY; MANGUN, 2006).

Em laboratório, a atenção espacial pode ser manipulada ao induzir o voluntário a acreditar que os estímulos aparecerão em um determinado local, e não em outros (orientação voluntária da atenção) ou ao atrair a atenção para determinado local apresentando estímulos sensoriais (orientação automática da atenção). Desta forma, a atenção pode ser manipulada por pistas que a direcionam, apresentadas antes do aparecimento do estímulo (GAZZANIGA; IVRY; MANGUN, 2006).

A atenção visual tem sido descrita ao longo dos anos por várias metáforas e/ou modelos, que tentam identificar aspectos essenciais desse fenômeno (AZEVEDO, 2009; CANTO-PEREIRA, 2006). São exemplos:

- “Holofote Atencional” ou spotlight: modelo proposto por Posner (1980), engloba duas das principais características da atenção visual:

- A atenção seria espacialmente delimitada;

- Existiria um custo temporal para o seu deslocamento.

De acordo com esse modelo, o foco atencional pouco provavelmente poderia ser dividido, comparando-se a um holofote de luz, que ilumina apenas um determinado local do espaço de cada vez.

- “Lente Zoom” ou zoom lens: proposto por Ericksen e St James (1986), sugere que o foco atencional é único, porém de tamanho variável e capaz de se adaptar à demanda sugerida pela tarefa a ser desempenhada. Segundo este modelo, o foco atencional apresentaria uma distribuição uniforme de recursos atencionais na área atendida. Quanto maior a área a ser atendida, menor a densidade de recursos atencionais disponíveis.

- “Gradiente atencional”: sugere que o tamanho, a forma e a densidade do foco atencional são variáveis, estando mais concentrados no centro e diminuídos na periferia (DOWNER; PINKER, 1985; LABERGE, 1995).

- “Modelo modificado de atenção visuo-espacial”: proposto por Kraft et al., (2005), sugere que é possível dividir a atenção espacial, com cada hemisfério cerebral atuando no controle de ambos os focos atencionais divididos; 
- “Chapéu Mexicano”: sugere que ao redor do holofote atencional haja um anel de inibição, circundado por uma periferia em que os recursos atencionais tenham um valor basal (MULLER et al., 2003).

- “Multifocal”: proposto por Cavanagh e Alvarez (2005), sugere que existem diversos focos atencionais independentes.

Um aspecto em comum de todos estes modelos é a distribuição espacial dos recursos atencionais no campo visual. A distribuição destes recursos não é determinada necessariamente pelo foveamento. Apesar de normalmente estar associada a ele, é possível dissociá-la para locais não foveados, na periferia do campo visual.

Um dos pioneiros a estudar questões relacionadas à atenção visual e a demonstrar a capacidade do sistema visual humano em direcionar a atenção para uma determinada área do campo visual, na ausência de movimentos oculares, foi Herman Von Helmholtz (1821-1894). Para demonstrar essa capacidade ele realizou o seguinte protocolo experimental: ao longo de todo o experimento, o voluntário deveria fixar o olhar em um pequeno ponto iluminado, na região central de uma grade com letras impressas não iluminadas. Na seqüência, um feixe luminoso, oriundo de uma faísca elétrica, iluminava por um período muito curto uma determinada região dentro desse conjunto de letras (Figura 6). Nesta situação, os observadores eram incapazes de identificar quais letras haviam sido iluminadas. Porém, quando era solicitado que os sujeitos direcionassem antecipadamente sua atenção para determinado local do campo visual, sabendo previamente que aquela seria a região iluminada, as letras eram identificadas, mesmo com o olhar fixo no ponto central. Dessa forma, o pesquisador concluiu que havia uma capacidade interna de direcionamento de recursos atencionais para determinada região do campo visual, independente do ponto de fixação ocular (POSNER; COHEN, 1984; REIS, 2010). 
Figura 6 - Protocolo experimental adotado por HelmHoltz.

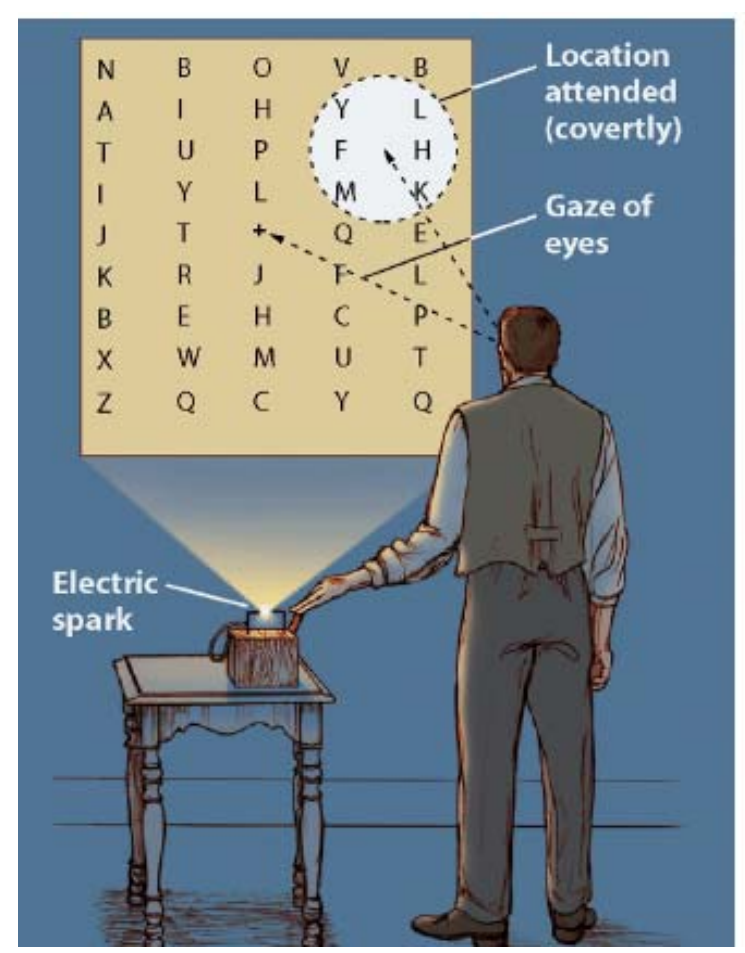

O observador era instruído a fixar seu olhar no centro da grade de letras e deveria orientar sua atenção previamente para uma determinada região da grade, que seria ilumina (REIS, 2010).

Outra questão muito debatida relacionada à orientação voluntária da atenção visual diz respeito à possibilidade da atenção ser dividida em duas ou mais regiões.

Trabalhos realizados em nosso laboratório (AZEVEDO, 2009; CANTO-PEREIRA et al., 2005, CANTO-PEREIRA, 2006) demonstraram uma clara divisão da atenção, mobilizada de maneira voluntária, com dois focos distintos, corroborando os achados de outros pesquisadores, favoráveis à possibilidade da divisão da atenção (AWN; PASHLER, 2000; KRAFT et al., 2005; MULLER et al., 2003). Nesses trabalhos realizados no laboratório foi aplicado um método inovador de estudo da distribuição da atenção no campo visual, medindo tempos de reação a estímulos visuais que podiam aparecer em diferentes pontos na tela do computador. Ao invés de seguir protocolos tradicionais, em que poucos pontos específicos são superamostrados, a aplicação de técnicas de análise geoestatística (YAMAMOTO, 2000) permitiu extrair a estrutura espacial dos dados obtidos, subamostrando muitos pontos distribuídos em uma área extensa do campo visual. A análise geoestatística interpola e alisa os dados, fornecendo uma imagem em que a estrutura espacial dos dados é evidenciada. Isto possibilita determinar as regiões nas quais a atenção está mais ou menos concentrada, interpretando os dados de tempos de reação como indicativos de concentração atencional: tempos de reação curtos correspondem a alta concentração atencional, e vice versa. Em outras 
palavras, o nível de atenção em qualquer ponto do campo visual pode ser estimado pelo tempo de reação ao estímulo visual que apareceu naquele ponto: quanto mais rápida for a resposta, maior é considerado o nível de atenção no ponto em questão (POSNER, 1980).

Uma alternativa à análise geoestatística é a análise por regiões de interesse (ROI), tradicionalmente realizada pela maioria dos trabalhos na literatura e que foi utilizada no presente trabalho.

Uma das maneiras mais utilizadas para mensurar o efeito de processos mentais como a atenção visual no processamento da informação é examinando o tempo que os indivíduos demoram para desempenhar determinada tarefa. Este método, conhecido como cronometria mental, foi proposto pela primeira vez por um pesquisador alemão chamado F.C. Donders, por volta do ano de 1850 (POSNER; RAICHLE, 1994). Para realizar esta análise, utiliza-se a medida do tempo de reação (TR), definido como o tempo entre o início da apresentação de um estímulo sensorial e o início da subseqüente resposta comportamental. Ele indica a rapidez do individuo em realizar a operação mental necessária para a execução de determinada tarefa, como por exemplo apertar o botão de um joystick em resposta ao aparecimento de um estímulo no campo visual. A velocidade das respostas aos estímulos em locais atendidos ou não atendidos é um índice de processamento relacionado à atenção (GAZZANIGA; IVRY; MANGUN, 2006). A partir das pesquisas realizadas por Helmholtz e outros pesquisadores pioneiros, sabe-se que o conhecimento prévio da posição de apresentação de um alvo ao qual se deve emitir uma resposta leva a uma melhora no desempenho. Além de melhorar a resposta à estímulos que aconteçam na posição previamente indicada, essa concentração de recursos também leva a um processamento menos eficiente dos estímulos que aconteçam em outras posições do campo visual (ARAÚJO; CARREIRO, 2009; POSNER, 1978).

De acordo com Posner (1978), a orientação prévia da atenção à uma região prédeterminada facilita a detecção de estímulos que apareçam nesta região e torna mais lenta a detecção de estímulos que apareçam em outras regiões. As diferenças observadas entre os tempos de reação em condições válidas (quando o estimulo aparece na posição indicada previamente), neutras (quando não há indicação prevendo a posição do alvo) e inválidas, (quando o estímulo aparece em outra posição, que não a indicada), segundo o pesquisador, não dependeriam de fatores retinianos e motores, mas sim de mecanismos centrais, envolvidos com a expectativa de ocorrência do estímulo em determinada região (ARAUJO; CARREIRO, 2009).

Em trabalhos realizados em nosso laboratório (AZEVEDO, 2010; CANTOPEREIRA, 2006), verificou-se, através de uma análise geoestatística, a capacidade de, 
voluntariamente, desvincular a atenção do ponto de fixação e alocar a atenção na região do espaço solicitada, seja ela na região central, na periferia esquerda ou direita, ou em ambos os lados, simultaneamente.

No presente trabalho pretende-se estender os estudos realizados anteriormente em nosso laboratório (AZEVEDO, 2009; CANTO-PEREIRA et al., 2004, 2005, 2006) para determinar se há diferenças entre dois grupos de voluntários: atletas profissionais na modalidade futebol de campo e não atletas (indivíduos que não praticaram atividades esportivas nos últimos 3 anos), no que diz respeito as capacidades perceptuais e aos efeitos da orientação voluntária da atenção.

\subsection{Atenção Visual e a Prática Esportiva}

Durante uma partida, um jogador de futebol tem um arranjo visual complexo à sua frente. Consideremos um jogador da posição de meio-campo, que está prestes a efetuar um passe para um companheiro de time. Espacialmente, existem muitos objetos, estímulos e eventos concorrendo pela sua atenção. É vantajoso atender a alguns destes estímulos (por exemplo à um jogador adversário, que está tentando interceptar o passe) e ignorar outros (por exemplo o juiz, que está posicionado, eventualmente, na mesma direção). Temporalmente, o arranjo visual está constantemente mudando. Em determinados momentos, sinais evidentes devem ser ignorados (como quando o adversário tenta mascarar suas reais intenções), e em outros momentos eles devem ser atendidos (quando o adversário realmente se coloca à frente, para tentar roubar a bola, por exemplo).

As situações descritas acima demonstram como os jogadores são confrontados por uma complexa, rápida e constante mudança no ambiente da partida. Em diversas situações o atleta deve ser capaz de desvendar qual será a ação dos adversários e companheiros de equipe e interpretar as informações provenientes da bola e dos outros jogadores. Devido à rapidez das jogadas, o tempo geralmente é escasso para a decisão da ação a ser executada, e muitas vezes torna-se necessário deduzir qual será a direção tomada pelos outros jogadores. Além do tempo escasso, as ações dos jogadores também sofrem o efeito da "pressão" realizada pelos adversários, que tentam restringir o espaço para a execução do gesto (WILLIAMS, 2000).

A capacidade de percepção do jogo em atletas baseia-se em fatores cognitivos que incluem, entre outros, a habilidade em utilizar estratégias visuais apropriadas para o processamento das informações. Jogadores experientes parecem conseguir extrair melhor as informações do ambiente, como a posição de adversários e companheiros de time e da bola. 
Essa habilidade permite o reconhecimento das características gerais do jogo de maneira rápida, facilitando a antecipação da ação dos demais jogadores e contribuindo para o bom desempenho na tarefa em questão (WILLIAMS, 2000).

Os jogadores devem ser capazes de tomar decisões e iniciar os movimentos rapidamente, baseando-se na percepção visual periférica e central (ANDO; KIDA; ODA, 2001).

Diversos pesquisadores buscaram estudar a dinâmica da atenção visual nos esportes e sugeriram a existência de melhores capacidades visuais e perceptivas em indivíduos esportistas do que em indivíduos não esportistas.

Os atletas mais experientes parecem utilizar seu conhecimento acerca do esporte que praticam para reduzir a incerteza sobre a relevância das pistas visuais e das possíveis respostas motoras (ABERNETHY, 1992). Exemplo dado por Enns e Richards (1997), que pode ser extrapolado para todos os esportes coletivos, é de um atacante de hóquei habilidoso que utiliza as informações provenientes do corpo do defensor para decidir se deve seguir o caminho da direita ou da esquerda, na hora da finta. Em contraposição, um jogador menos experiente pode basear sua decisão em uma pista menos confiável para decidir o movimento futuro do defensor. A mesma coisa acontece no futebol de campo, esporte que foi estudado nesse trabalho.

Uma das habilidades cognitivas que desempenha papel crucial na redução da incerteza relativa às ações futuras é a atenção visuo-espacial. Os eventos aos quais os atletas devem ou não prestar atenção, em uma determinada situação, influenciam fortemente o desempenho dos jogadores. A capacidade de fornecer rapidamente respostas motoras a sinais visuais em situações complexas é qualidade indispensável nos esportes (CARREIRO; FERREIRA; MACHADO-PINHEIRO, 2009).

Na prática esportiva, a capacidade de orientar a atenção independente do movimento ocular (exercício da atenção encoberta) é fator primordial, pois os jogadores devem ser capazes de, a todo o momento, olhar para determinado local, objeto ou evento (posição da bola, do jogador da sua equipe, do jogador adversário e etc) e, ao mesmo tempo, prestar atenção a eventos que ocorram simultaneamente em outros locais.

Diversos estudos abordaram a relação entre as habilidades esportivas e a atenção visual encoberta. Enns e Richards (1997), em seu artigo de revisão, descrevem algumas dessas pesquisas. Em um dos estudos mais antigos, boxeadores da seleção francesa foram comparados com adultos estudantes de Educação Física, em uma tarefa de orientação voluntária da atenção visual. As respostas dos atletas e dos estudantes foram parecidas em 
todos os aspectos estudados, exceto no fato que os boxeadores mostraram menores benefícios da orientação voluntária da atenção (NOUGIER; RIPOLL; STEIN, 1989). O mesmo resultado também foi encontrado em outros estudos. Em uma comparação realizada entre boxeadores, penta-atletas, arqueiros e estudantes, todos os grupos de atletas novamente apresentaram menor efeito da orientação da atenção do que o grupo de estudantes. Em outra comparação, com tenista experientes vs não experientes, em 3 diferentes idades (13, 16 e 25 anos), os efeitos da pista que previa a localização correta do estímulo foram novamente menores para o grupo de atletas mais experientes (NOUGIER; AZEMAR; STEIN, 1992). Finalmente, em uma comparação entre jogadores de voleibol profissional e estudantes universitários não atletas, novamente foram demonstrados menores efeitos causados pela orientação da atenção nos atletas, comparando-se com os voluntários não atletas (CASTIELLO; UMILTA, 1992). Uma hipótese para a ocorrência destes resultados, levantada por Castiello e Umiltà (1992), é que atletas seriam capazes de alterar o local de atenção mais rapidamente do que não atletas, não apresentando, portanto, os mesmos níveis de benefício de pistas preditivas do que os não atletas Em outras palavras, o desempenho dos atletas seria melhor, mesmo sem o auxílio das dicas externas.

Carreiro, Ferreira e Machado-Pinheiro (2009), em uma comparação entre jogadores de voleibol e não atletas demonstraram resultados similares. Os atletas apresentaram tempos de reação mais curtos em comparação ao grupo de não esportistas, de cerca de 50 ms, durante uma tarefa de orientação voluntária da atenção, apesar de ambos os grupos terem apresentado diminuição no tempo de resposta em função da orientação prévia da atenção. As comparações evidenciaram também que a diferença entre as condições válidas e inválidas foi significativa no grupo de não esportistas, mas não no grupo de jogadores de voleibol. Esses resultados, segundo os autores, poderiam sugerir que os atletas são mais rápidos em reorientar sua atenção para o lado "incorreto" após uma pista falsa, diminuindo os prejuízos desta condição. Nesse mesmo trabalho foi realizada uma tarefa de orientação automática da atenção. Os tempos de reação dos atletas, apesar de terem sido novamente menores do que o grupo não atletas (17ms), não apresentaram diferenças significativa. Os autores pressuporam que o direcionamento voluntário da atenção poderia ser mais treinado do que o automático, e que o treinamento ao qual os atletas são submetidos melhoraria os tempo de reação na identificação dos estímulos.

Segundo Cereatti, Casella, Manganelli e Pesce (2008), diversos estudos mostraram que atletas experientes, praticantes de esportes caracterizados por alta demanda atencional visual, mostram maior flexibilidade na alocação da atenção visual. Nougier, Azemar e Sten 
(1992) e Enns e Richards (1997), citados novamente nesse estudo, demonstraram que quanto mais experientes os atletas, menor é o efeito atencional observado. Para os autores, o efeito atencional se refere às diferenças nos tempos de reação observados quando o estímulo ocorre na área atendida (onde há a expectativa do aparecimento) e quando ele ocorre em áreas não atendidas.

Outros autores demonstraram diferenças entre os tempos de reação visual de atletas e não atletas. Ghuntla et al. (2012), em uma comparação entre atletas de basquetebol e não atletas, relataram que os atletas apresentam tempos de reação menores do que os não atletas em tarefas de tempos de reação simples e tempos de reação escolha. Segundo os autores, o tempo de reação é um importante indicador do tempo de resposta para qualquer tipo de estímulo, e deve ser o menor possível em atividades esportivas e em outras atividades que dependam da tomada rápida de decisões, como por exemplo, dirigir. Para os autores, apesar dos mecanismos do processamento das informações visuais no exercício não estarem totalmente esclarecidos, existem algumas hipóteses para a ocorrência destas diferenças entre os grupos. A hipótese mais difundida seria a de que indivíduos que se exercitam de uma maneira moderada a intensa apresentariam maiores níveis de fluxo sanguíneo no cérebro. Esse fluxo sanguíneo cerebral elevado resultaria em melhora nas funções cognitivas, devido ao aumento da oferta de nutrientes necessários, como o oxigênio e a glicose (ETNIER et al., 1997).

Vaghetti, Roesler e Andrade (2007), em uma comparação entre surfistas profissionais e iniciantes em tarefas de tempo de reação simples auditivo e visual, mostraram que os surfistas experientes foram significativamente mais rápidos do que os iniciantes nas tarefas de tempo de reação visual.

Os resultados apresentados nos estudos citados parecem demonstrar que os atletas possuem melhores capacidades perceptuais do que não atletas. Porém, esta ainda é uma questão em aberto, e algumas pesquisas, citadas a seguir, encontraram resultados controversos.

Guizani et al., (2006) realizaram uma comparação entre atletas de esgrima e indivíduos sedentários. Cada grupo desempenhou tarefas de tempo de reação simples em situação de repouso e pedalando uma bicicleta ergométrica, em diferentes faixas de esforço. $\mathrm{Na}$ situação de repouso e de exercício físico não foram encontradas diferenças significativas entre os grupos. Os autores concluíram que os tempos de reação simples dos atletas e dos não atletas não apresentam variação diante dos diferentes níveis de esforço. 
Em uma comparação entre atletas de handebol experientes, iniciantes e atletas de modalidades individuais, em diferentes tarefas atencionais, Memmert, Simons e Grimme (2009) mostraram que atletas experientes de handebol não apresentavam maior amplitude de atenção no campo visual, e que as diferenças entre os tipos de modalidade (coletiva e individual) não afeta a habilidade em identificar os estímulos na periferia do campo visual, longe do local de fixação. O grupo de atletas também não foi melhor do que os iniciantes na habilidade de dividir a atenção entre o foco de fixação e outras áreas do campo visual.

Estes achados diferem de evidências prévias de que os atletas são melhores em habilidades atencionais básicas e é mais consistente com a idéia de que os atletas experientes possuem vantagens apenas no que diz respeito a tarefas específicas do esporte, e não nas habilidades perceptuais básicas (ABERNETHY; NEAL; KONING, 1994; MEMMERT; SIMONS; GRIMME, 2009).

Não há explicações definitivas para a discrepância entre essas observações. O presente trabalho, por exemplo, utilizou um protocolo experimental que já havia sido utilizado em nosso laboratório anteriormente, em outro estudo. Apesar das condições experimentais serem muito similares, os resultados apresentaram diferenças significativas, decorrentes, provavelmente, de pequenas diferenças nas instruções fornecidas aos voluntários. Enquanto durante os experimentos anteriores foi dito de maneira explicita aos voluntários que prestassem atenção a determinadas regiões do campo visual, no presente trabalho a instrução foi de que a concentração de estímulos seria maior em determinadas regiões, induzindo os voluntários a direcionar sua atenção para aqueles locais. Existem relatos na literatura de que bastaria os voluntários possuírem informações sobre a probabilidade de aparecimento de estímulos em determinadas regiões para que os tempos de reação à estes estímulos fossem mais curtos. Segunda a literatura, mesmo sem obter instruções explícitas, apenas ao descobrir ao longo do experimento que determinada região apresentaria maior densidade de estímulos, os tempos de reação dos voluntários à ocorrência dos estímulos diminuiria (JAKOBS, WANG, DAFOTAKIS, GREFKES, ZILLES, EICKHOFF, 2009). Interessante, portanto, verificar a robustez desses achados e contribuir para esclarecer essas questões. 


\section{OBJETIVOS}

2.1 Objetivos gerais

Estudar atletas e não atletas em suas capacidades de orientação voluntária da atenção visuo-espacial, avaliada por tempos de reação simples a estímulos visuais nas condições de:
a) atenção difusa;
b) atenção manifesta;
c) atenção encoberta (direcionada a direita ou a esquerda) e;
d) atenção dividida

\subsection{Objetivos específicos}

a) Verificar se há diferenças entre atletas e não atletas, no que diz respeito aos tempos de reação aos estímulos visuais;

b) verificar se há diferenças entre atletas e não atletas na orientação voluntária da atenção visuo-espacial mobilizada voluntariamente. 


\section{JUSTIFICATIVA}

Existe um crescente interesse no desenvolvimento de pesquisas abordando as características inerentes à percepção e atenção visual nos esportes (WILLIAMS, 2000).

Porém, poucos são os estudos que investigaram os tempos de reação a estímulos visuais apresentados em diferentes posições do campo visual, comparando atletas de futebol de campo e não atletas.

Nesse caminho, uma questão importante a ser levantada é se de fato a prática esportiva é capaz de melhorar as capacidades atencionais em diferentes situações, como quando os estímulos são apresentados de uma maneira difusa, manifesta, encoberta e dividida. Existe ainda a possibilidade de que alguns indivíduos se destaquem no esporte justamente por apresentarem estas habilidades inatas. Uma comparação entre atletas e não atletas é um primeiro passo na busca destas respostas.

O arranjo visual ao qual os jogadores são submetidos sugere que o grupo de atletas parece possuir (ou ter desenvolvido) maiores habilidades perceptuais do que não atletas, já que devem ser capazes de seguir o movimento da bola e dos outros jogadores, que se apresentam a diferentes distâncias (ANDO; KIDA; ODA, 2001).

Posner (1980) relatou que os tempos de reação a estímulos periféricos são menores nas regiões onde se espera que os estímulos apareçam e mais longos nas regiões onde não se espera o aparecimento.

No futebol de campo, durante os jogos e treinamentos, os jogadores precisam prestar atenção a todos os estímulos que aparecem no campo visual: os que ocorrem em regiões esperadas e os que ocorrem em regiões inesperadas.

Por isso, mensuramos os tempos de reação em diferentes situações, para observar as diferenças entre atletas profissionais de futebol de campo e não atletas, no que diz respeito ao efeito da orientação voluntária da atenção visual. 


\section{MATERIAIS E MÉTODOS}

\subsection{Voluntários}

Participaram dos experimentos 30 voluntários do sexo masculino, com faixa etária entre 18 e 30 anos, divididos em dois grupos: atletas profissionais (AP) e não atletas (NA) na modalidade futebol de campo. Os sujeitos experimentais apresentavam dominância manual e ocular direita. Após o esclarecimento dos procedimentos e preenchimento do Termo de Consentimento Livre e Esclarecido (ANEXO A) e da Entrevista Introdutória ao Estudo (ANEXO B), os sujeitos experimentais foram submetidos ao seguinte procedimento:

- teste de dominância ocular: todos os experimentos foram realizados na situação monocular. O olho esquerdo (não dominante) foi ocluído por um protetor ocular hipoalergênico para oclusão oftalmológica da marca Oftam.

- inventário de dominância lateral de Edimburgo: versão abreviada do Inventário de Dominância Lateral de Edimburgo (OLDFIELD, 1971), utilizado para a avaliação da preferência lateral. Teste constituído por 10 questões sobre a preferência lateral na execução de tarefas motoras realizadas usualmente pela maioria das pessoas (ANEXO C). O critério de exclusão foi escore superior a +40.

Os grupos estudados foram formados por:

Grupo Atletas Profissionais (AP): 15 atletas profissionais de futebol de campo do Nacional Atlético Clube, clube paulistano que disputa atualmente a terceira divisão (A3) do Campeonato Paulista, realizado pela Federação Paulista de Futebol.

Grupo Não Atletas (NA): 15 voluntários que não praticaram nenhuma atividade esportiva regular nos últimos 3 anos (não controlamos os níveis de atividade física, apenas de atividades esportivas). Os voluntários foram recrutados na Universidade de São Paulo e eram alunos de graduação e pós-graduação das Faculdades de Física, Química, e do Instituto de Ciências Biomédicas. 


\subsection{Sala de Teste}

As sessões experimentais foram realizadas em dois ambientes diferentes (Figura 7). O grupo controle, formado pelos voluntários que não realizavam atividades esportivas regulares, executou os experimentos em uma sala de testes localizada no Laboratório de Fisiologia do Comportamento, do Instituto de Ciências Biomédicas (prédio III), na Universidade de São Paulo, em ambiente escuro e com isolamento acústico. O grupo experimental, formado pelos atletas de futebol de campo, realizou os experimentos em uma sala cedida pela diretoria do Nacional Atlético Clube, no centro de treinamento do Clube, localizada no bairro Barra Funda, na cidade de São Paulo. A sala também possuía isolamento acústico e os testes foram realizados em ambiente escuro. A escolha de realizar os experimentos na sede do clube ocorreu para não prejudicar a rotina de treinamentos dos atletas, que seguindo o calendário de competições, estavam disputando a série A3 do Campeonato Paulista de Futebol de Campo, válido pela Federação Paulista de Futebol.

Em ambos locais os testes aconteceram no período da manhã (entre 8h e 12h). Os sujeitos foram posicionados centralmente em frente ao monitor e mantidos a uma distância de 57 centímetros da tela do computador, durante todos os experimentos, com a cabeça estabilizada por um apoio de queixo e testa (Figura 8).

Figura 7 - Salas de teste

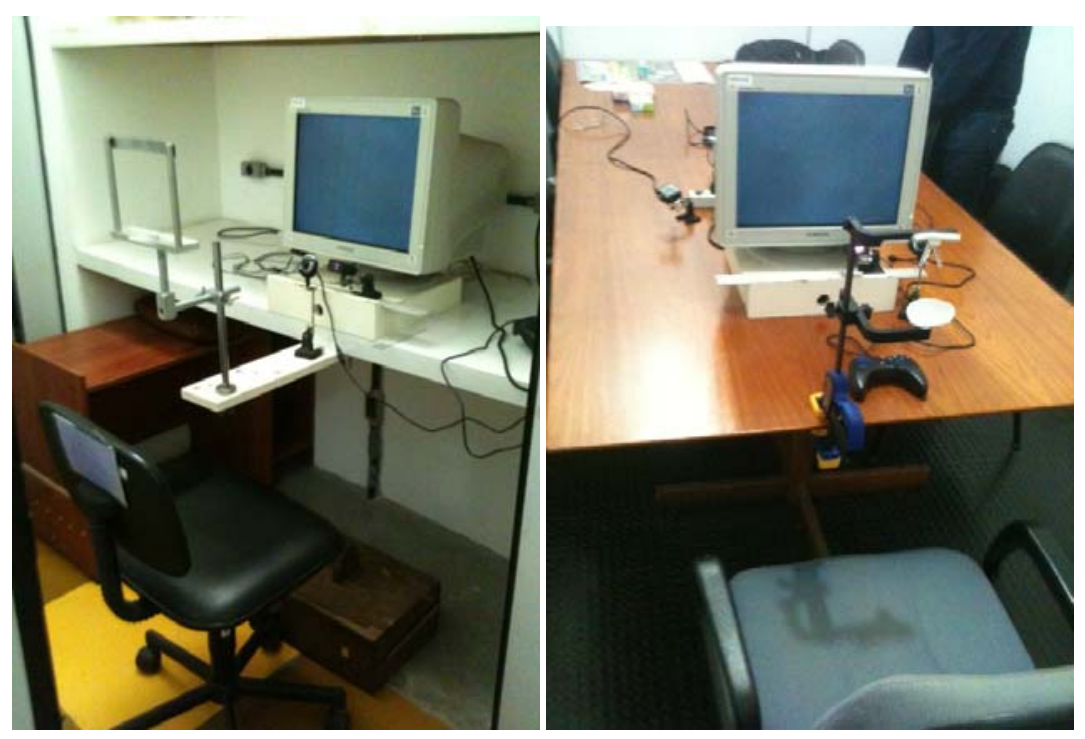

Salas de teste no laboratório de fisiologia do comportamento, no ICB III (a esquerda) e sala de testes no Nacional Atlético Clube (a direita), com os componentes utilizados nos experimentos. 
Figura 8 - Situação experimental, com os voluntários em posição.

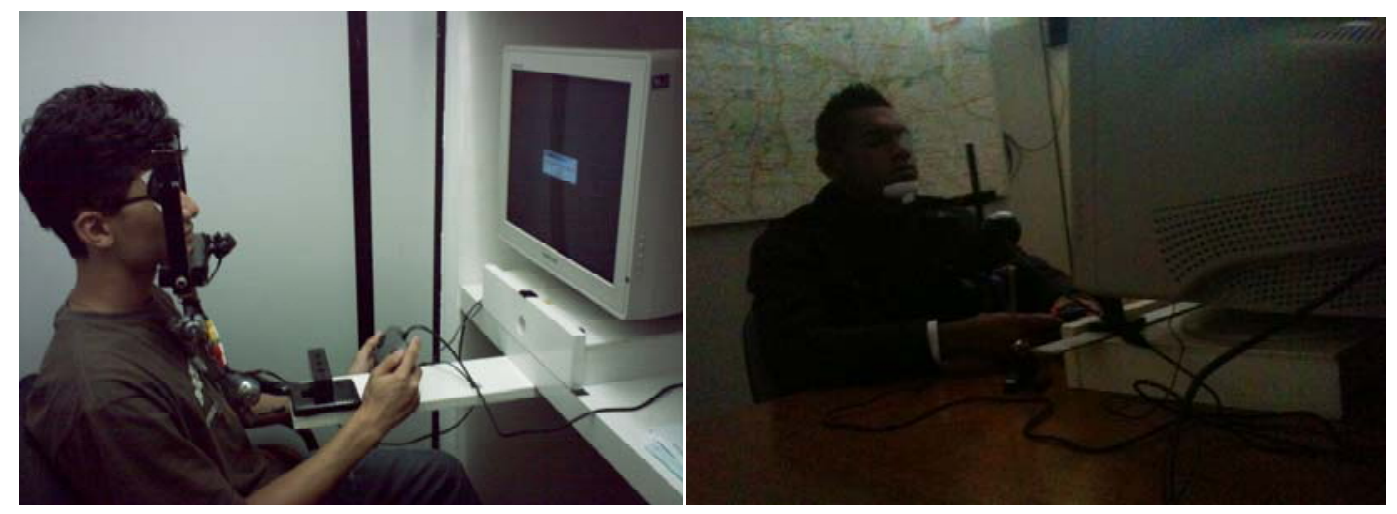

Sala do laboratório de Fisiologia do Comportamento no ICB III (a esquerda) e sala do Nacional Atlético Clube (a direita).

\subsection{Equipamentos}

Os estímulos visuais foram apresentados em uma tela CRT plana de 19", controlada por um notebook Dell Ispiron 1564, que também registrou as respostas dos voluntários. A apresentação dos estímulos e o registro das correspondentes respostas foram gerenciados pelo software livre PSYCHOPY, que garante, em princípio, precisão de milissegundos. Aliado à este software, foi implementado um rastreador do olhar (eye tracker), construído com peças disponíveis no comércio local, rodando um software livre, ITU-GAZE TRACKER, disponibilizado pela Universidade de Tecnologia da Informação de Copenhague, na Dinamarca (Figuras 9 e 10).

Figura 9 - Componentes de montagem do Eye Tracker.

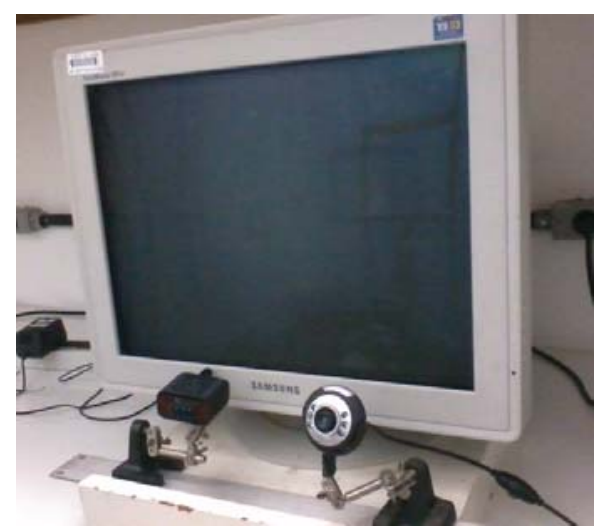

Abaixo do monitor, o iluminador infravermelho e a câmera adaptada, peças encontradas no comércio local.

Para integrar o rastreador do olhar ao programa PsychoPy foi desenvolvido um programa em C Sharp, denominado EEye (Experimental Eye - figuras 11 e 12), que registra os dados fornecidos pelo eye tracker, gravando os tempos e as direções do olhar ao longo de 
todo o experimento. Em cada tentativa são registradas no mínimo 20 e no máximo 80 aquisições (dependendo da duração das tentativas) relativas às posições oculares. O programa EEye analisa os dados e identifica perdas de fixação durante a realização de cada tentativa apresentada pelo PsychoPy. O critério para validar ou invalidar uma tentativa por perda de fixação é um desvio maior de 3,6 graus, por 5 aquisições ou mais (dentre as 20 à 80 aquisições). Utilizou-se este critério devido a frequência de captura do eye tracker (23 frames por segundo, equivalente à cerca de $44 \mathrm{~ms}$. Desta forma, 5 aquisições corresponderiam a aproximadamente $220 \mathrm{~ms}$.

Figura 10 - Monitoramento ocular realizado pelo eye tracker construído no laboratório.

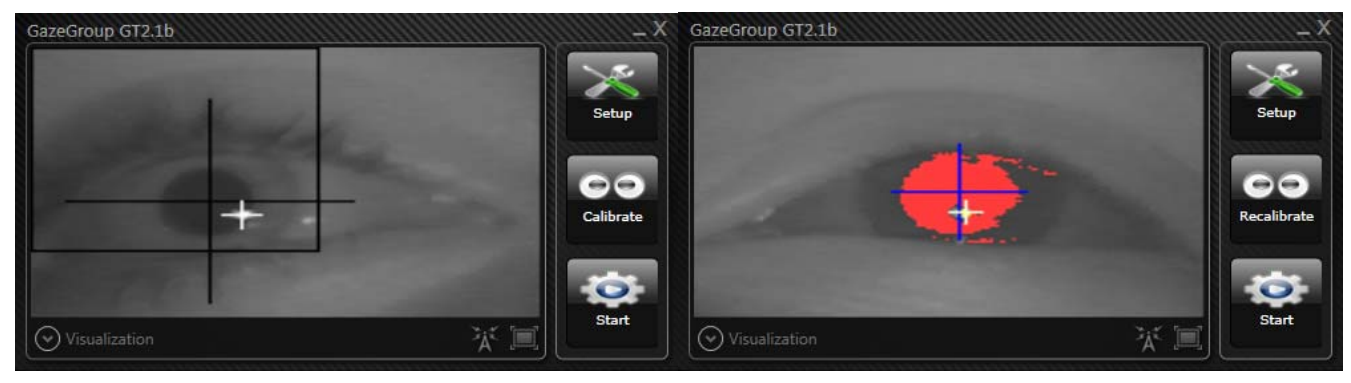

Figura 11 - EEye registrando as tentativas válidas e inválidas em tempo real

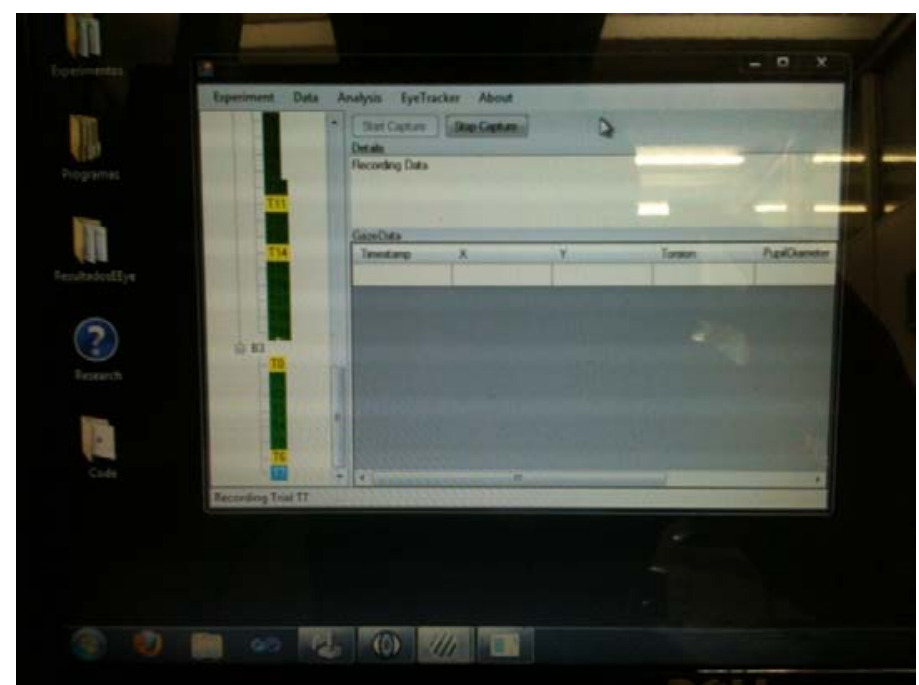

Do lado esquerdo as tentativas T11 e T14 a serem repostas por perda de fixação, marcadas em amarelo. As demais tentativas, marcadas em verde, são válidas. 
Figura 12 - Registro dos dados fornecidos pelo rastreador do olhar relativos a cada tentativa, mostrados pelo programa EEye.

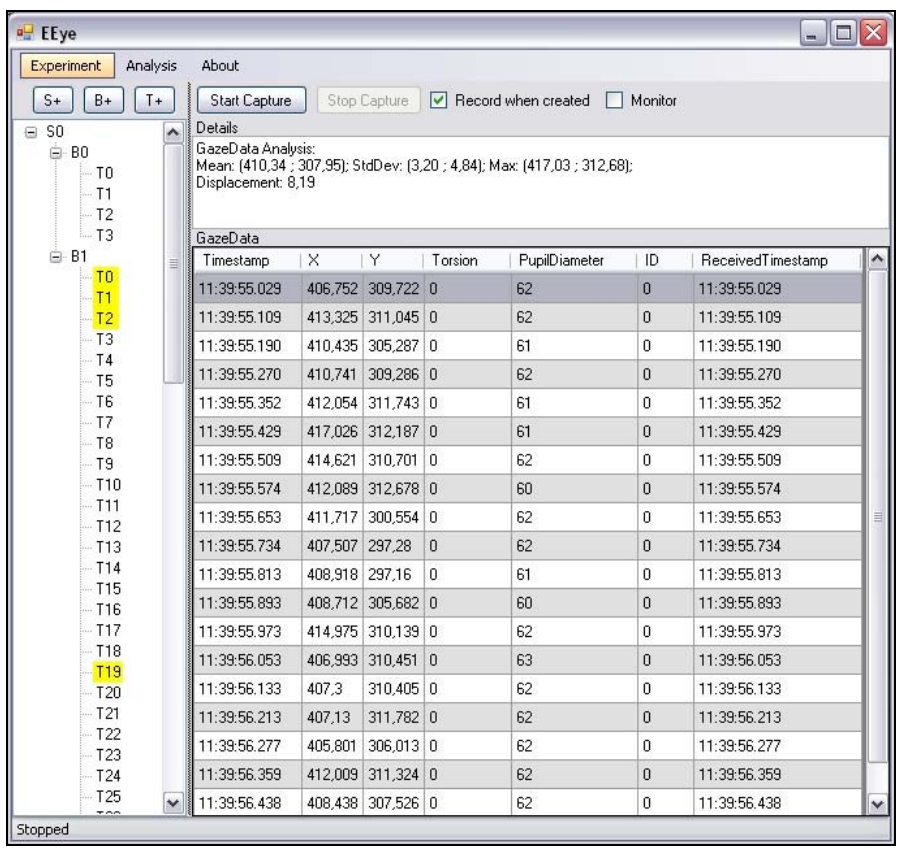

\subsection{Procedimentos}

Tempos de reação à estímulos visuais são uma medida confiável e tradicionalmente utilizada para quantificar a atenção visual. Apresentamos estímulos visuais dispostos em uma grade regular com 82, 154 ou 158 pontos amostrais (dependendo do experimento), abrangendo sempre de forma contínua um ângulo visual de $26^{\circ}$ (na direção horizontal) e $18^{\circ}$ (na direção vertical). O tempo de reação simples ao aparecimento de cada um dos pontos foi o critério de avaliação da concentração de atenção em cada local. Tempos de reação menores indicaram maior concentração atencional no ponto onde o estímulo apareceu.

O protocolo experimental contou com uma série de cinco experimentos, nos quais os voluntários deviam sempre olhar para uma cruz, localizada no centro do monitor, e apertar o botão de um joystick (Figura 13) com o dedo indicador da mão direita (dominante) o mais rápido possível em resposta ao aparecimento do estímulo imperativo. 
Figura 13 - Joystick utilizado pelos voluntários durante as tarefas

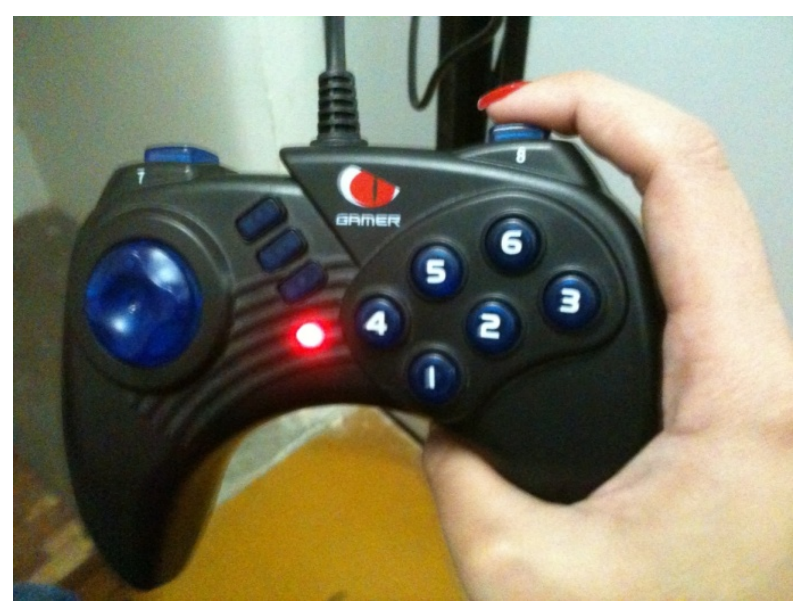

Os experimentos realizados foram os seguintes:

\section{- Experimento I - Estudo da Atenção Difusa}

Nessa condição os estímulos foram apresentados de maneira uniforme em toda a tela do monitor;

\section{- Experimento II - Estudo da Atenção Manifesta}

Nesse experimento os estímulos foram apresentados com maior densidade no centro da tela do computador, nas imediações do ponto de fixação;

\section{- Experimentos III e IV - Estudo da Atenção Encoberta}

Nessas condições a maior densidade de estímulos aconteceu em regiões periféricas laterais da tela do computador, a esquerda e a direita, respectivamente.

\section{- Experimento V - Estudo da Atenção Dividida}

Nesse experimento os estímulos foram apresentados com maior densidade em ambas as regiões periféricas laterais da tela do computador, de maneira simultânea.

A figura 14 mostra o diagrama temporal da distribuição dos estímulos em todos os experimentos. O intervalo entre os alvos foi aleatorizado entre $750 \mathrm{~ms}$ e $1500 \mathrm{~ms}$. 
Figura 14 - Diagrama temporal da apresentação dos estímulos, em todos os experimentos.

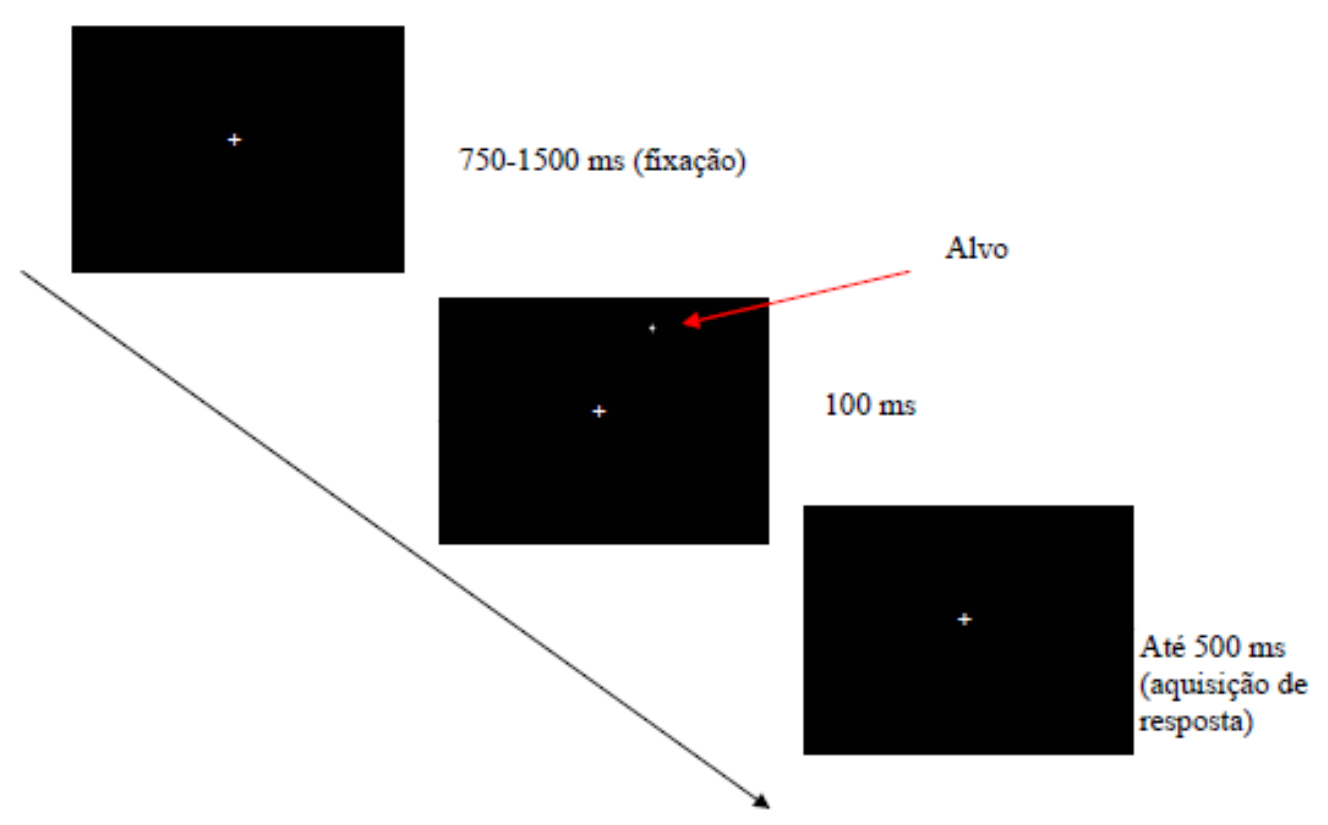

Antes da coleta dos dados de cada experimento, os voluntários foram submetidos a uma sessão de treino (com 20 tentativas aleatorizadas) nos procedimentos e foram sempre instruídos a manter a cabeça imóvel e o olhar fixo em uma pequena cruz localizada no centro da tela (Figura 14). Durante todas os experimentos telas de instruções foram apresentadas aos voluntários (ANEXO D).

Em todos os experimentos foi medido o tempo de reação simples em resposta ao aparecimento de um estímulo visual, com ângulo visual de $0,2^{\circ}$ e luminância de $80 \mathrm{~cd} / \mathrm{m}^{2}$, contra um fundo preto de $0 \mathrm{~cd} / \mathrm{m}^{2}$. O estímulo foi apresentado em diferentes posições na tela do computador, sempre com a duração de $100 \mathrm{~ms}$.

Foram consideradas respostas válidas aquelas que ocorreram dentro da faixa $150 \mathrm{~ms}-$ $500 \mathrm{~ms}$ à partir do aparecimento do alvo. As respostas que ocorreram abaixo de $150 \mathrm{~ms}$ foram consideradas antecipações e as respostas acima de $500 \mathrm{~ms}$ foram consideradas não respostas. As tentativas invalidadas por antecipações e não respostas foram repostas ao final dos blocos de cada experimento, pelo PshychoPy, em um novo bloco, junto com as tentativas invalidadas por desvios na fixação ocular da cruz de fixação, identificadas pelo programa EEye.

A figura 15 (A-E) mostra as posições em que os estímulos foram apresentados durante os cinco experimentos. Cada ponto foi apresentado uma única vez, para cada voluntário (exceto quando tiveram que ser repostos). 
Exceto no experimento I (atenção difusa), nos demais experimentos os voluntários foram instruídos a prestar atenção no interior da(s) moldura(s) cinza(s), presente(s) na tela do computador, através da informação de que os estímulos apareceriam mais vezes no interior destas molduras.

No experimento I (Figura 15-A), os estímulos foram apresentados em uma grade de 82 tentativas, de mesma densidade, igualmente distribuídos na tela do computador. Esse experimento funcionou como linha de base dos tempos de reação, em função das diferentes posições de apresentação dos estímulos. Neste caso, portanto, não se esperaria um foco atencional preferencial, e a atenção estaria espacialmente difusa.

No experimento II (Figura 15-B), 158 estímulos foram apresentados, com maior densidade no centro da tela do computador, na região central que compreende um ângulo visual de $4^{\circ} \times 4^{\circ}$. Essa região foi delimitada por uma moldura cinza, com luminância de $20 \mathrm{~cd} / \mathrm{m}^{2}$. A probabilidade de aparecimento de estímulos dentro dessa área foi maior do que no restante do monitor, favorecendo desta forma o direcionamento do foco atencional para o centro da tela.

Nos experimentos III (Figura 15-C) e IV (Figura 14-D) foram apresentados 158 estímulos, com maior densidade no lado esquerdo e direito do monitor, respectivamente. Nessas regiões foi posicionada uma moldura cinza, também de luminância de $20 \mathrm{~cd} / \mathrm{m}^{2}$, na área que se encontra à $10^{\circ}$ (horizontalmente) do centro da tela, em uma região de ângulo visual de $4^{\circ} \times 4^{\circ}$. Dentro da região delimitada pela moldura houve maior probabilidade de aparecimento de estímulos do que no restante do monitor, provocando, desta forma, o direcionamento do foco atencional para um dos lados da tela.

No experimento V (Figura 15-E), os estímulos foram apresentados em uma grade de 154 pontos, com maior densidade nos dois lados do monitor (direito e esquerdo). Neste experimento, as áreas do monitor que se encontram à $10^{\circ}$ de excentricidade, compreendendo uma região de $4^{\circ} \times 4^{\circ}$, delimitadas por duas molduras cinza (com luminância de $20 \mathrm{~cd} / \mathrm{m}^{2}$ ), apresentaram maior probabilidade de aparecimento de estímulos do que o restante do monitor, fazendo com que o foco atencional estivesse dividido, direcionado tanto para o lado direito como para o lado esquerdo da tela do computador. 
Figura 15 - Grade de estímulos utilizada durante os cinco experimentos.

A
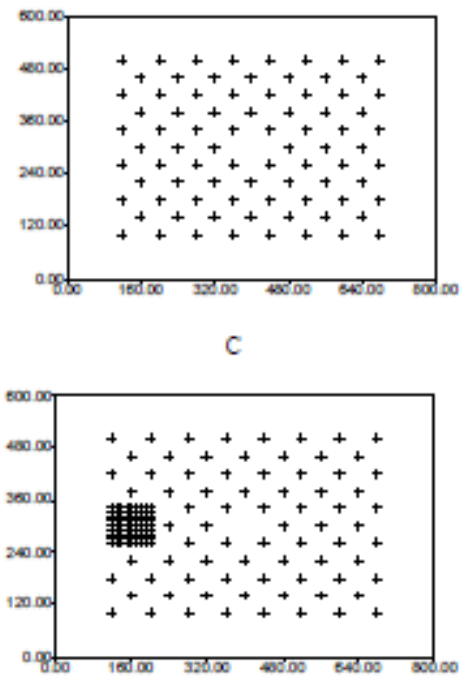

B

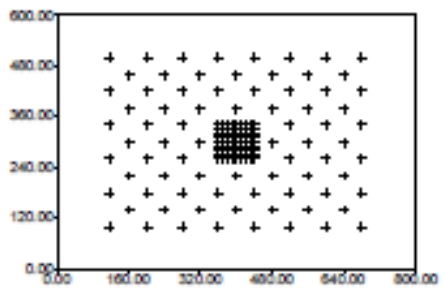

D

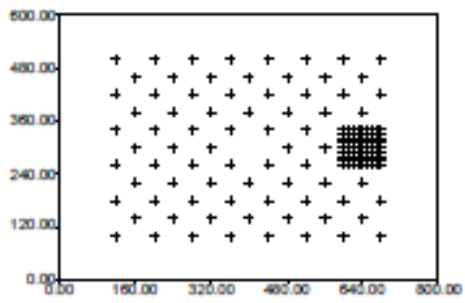

E

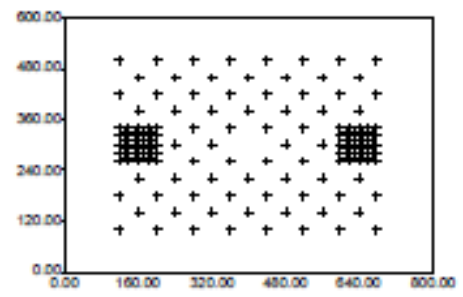




\section{ANÁLISE DOS DADOS}

5.1 Análise por Regiões de Interesse (ROI)

Optamos por analisar os dados aplicando testes utilizados nos experimentos tradicionais: teste $\mathrm{t}$ de Student na comparação dos dois grupos em bloco (atletas vs. nãoatletas) e Anova na comparação de múltiplos grupos, com diversos fatores, agregando os tempos de reação em resposta aos estímulos que ocorreram em cada experimento e em regiões de interesse (dentro das molduras, para onde a atenção foi previamente orientada) e fora da região de interesse, realizando desta forma uma comparação entre os tempos de reação nas duas condições. Se os tempos de reação aos estímulos que aparecerem dentro da região das molduras forem menores, pode-se dizer que ocorreu uma concentração atencional dentro da área de interesse, (no caso dentro da moldura), e vice-versa.

A magnitude do efeito atencional refletido pelas diferenças entre os tempos de reação dentro e fora da moldura e das diferenças entre os tempos de reação médios dos grupos foram analisada estatisticamente e os efeitos que alcançaram a probabilidade de erro do tipo I (aceitar como verdadeiro um efeito que é falso) menor ou igual a 0,05 (5\%) foram aceitos como significativos.

Para realizar as análises estatísticas utilizamos o software MATLAB. Os gráficos foram construídos no software GRAPHPAD PRISM. 


\section{RESULTADOS}

6.1 Experimento I - Atenção Difusa

\subsubsection{Atletas Profissionais vs Não Atletas (Tempos de Reação Médios)}

No experimento I, situação em que os estímulos foram igualmente distribuídos na tela do computador, o grupo atletas profissionais (AP) apresentou menores tempos de reação médios (diferença de $34 \mathrm{~ms}$ ) do que o grupo não atletas (NA), conforme mostrado no gráfíco 1.

Gráfico 1 - Comparação entre os tempos de reação médios do grupo atletas profissionais (AP) e do grupo não atletas (NA) no Experimento I (Atenção Difusa).

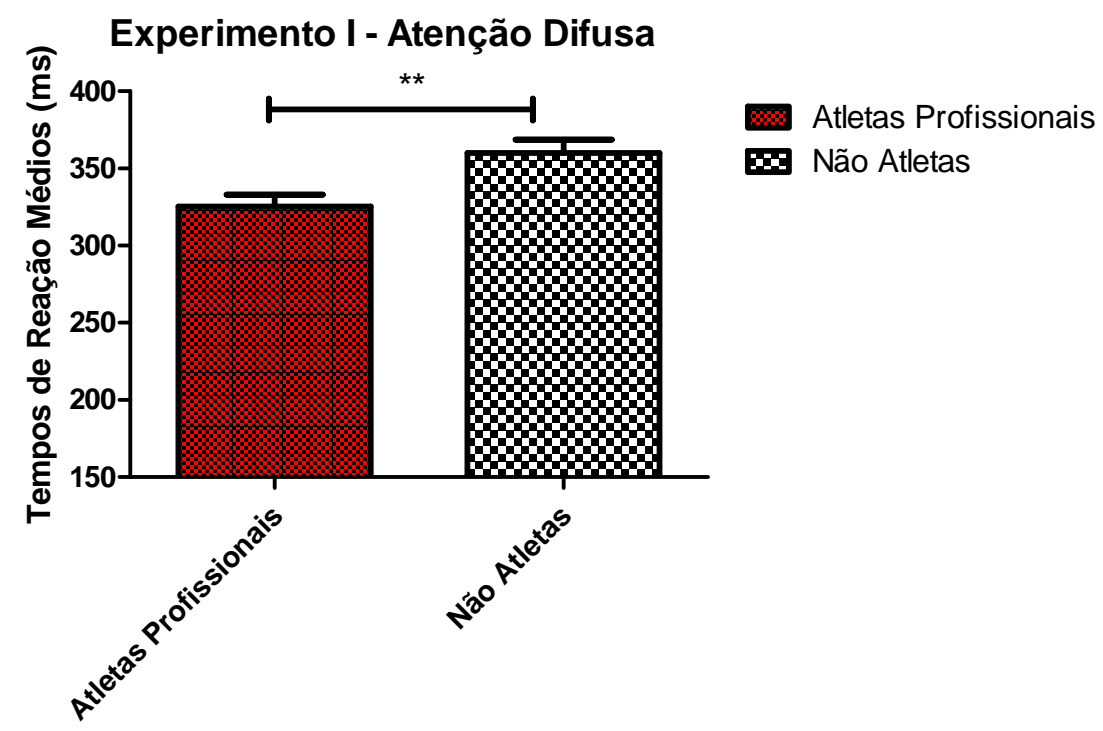

O tempo de reação médio do grupo AP foi $325 \mathrm{~ms}$ (EP: $\pm 8 \mathrm{~ms}$ e DP: 31$)$ e do grupo NA foi $360 \mathrm{~ms}$ (EP: $\pm 9 \mathrm{~ms}$ e DP: 33).

A análise estatística (teste $t$ de Student) revelou que a diferença entre os grupos foi significativa ( $\mathrm{p}=0,0057)$, indicando que os atletas foram mais rápidos do que os não atletas nessa tarefa. Esse experimento representa uma linha de base dos tempos de reação em função das diferentes posições de apresentação dos estímulos em relação ao ponto de fixação. 
6.2 Experimento II - Atenção Manifesta

\subsubsection{Atletas Profissionais vs Não Atletas (Tempos de Reação Médios)}

Nesse experimento os estímulos foram apresentados com maior densidade no centro da tela do monitor, facilitando o direcionamento do foco atencional para essa região. O grupo atletas profissionais (AP) novamente apresentou tempos de reação médios menores (diferença de $27 \mathrm{~ms}$ ) do que o grupo não atletas (NA), conforme mostrado no gráfico 2.

Gráfico 2 - Comparação entre os tempos de reação médios do grupo atletas profissionais (AP) e do grupo não atletas (NA) no Experimento II (Atenção Manifesta).

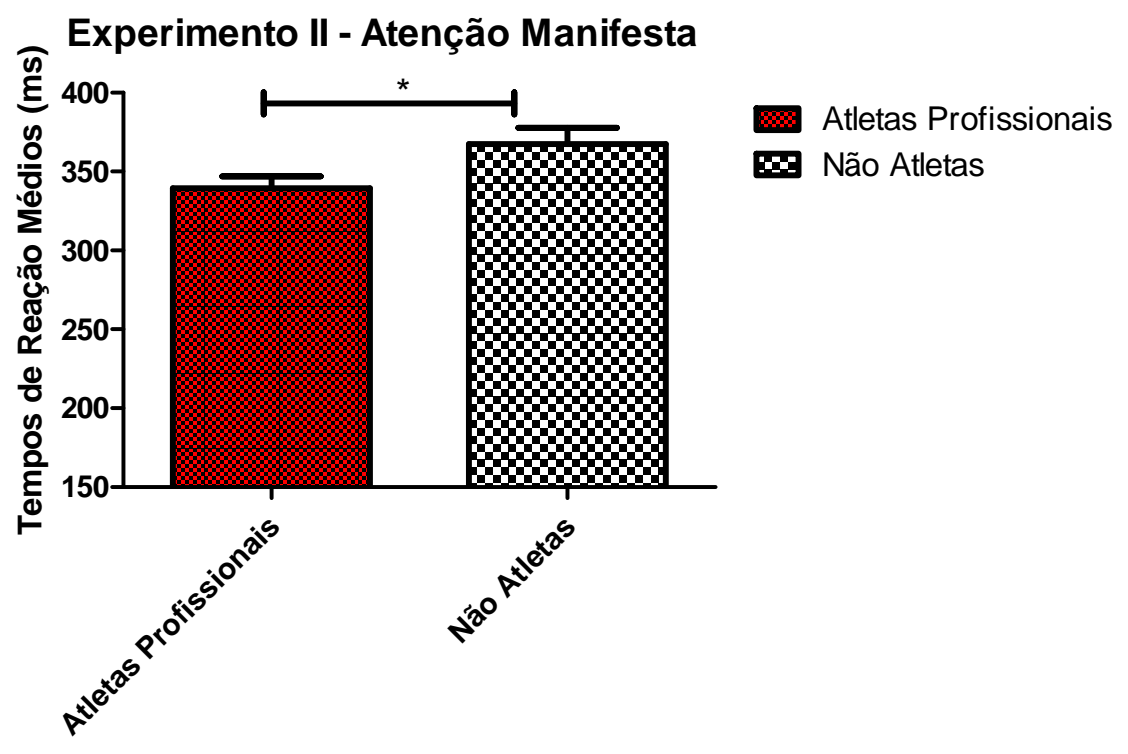

O tempo de reação médio do grupo AP foi $340 \mathrm{~ms}$ (EP: \pm 7 ms e DP: 29) e do grupo NA foi 367 ms (EP: $\pm 10 \mathrm{~ms}$ e DP: 41).

A análise estatística (teste $t$ de Student) novamente demonstrou diferença significativa entre os grupos $(p=0,04)$, indicando que os atletas profissionais foram mais rápidos do que os não atletas nessa condição experimental.

\subsubsection{Orientação Voluntária da Atenção}

Ambos os grupos apresentaram tempos de reação médios menores aos estímulos que apareceram no interior da moldura (região para onde a atenção foi orientada voluntariamente), 
do que aos estímulos que apareceram nas demais regiões (fora da moldura). A diferença nas médias foi de $17 \mathrm{~ms}$, para os dois grupos.

Gráfico 3 - Comparação entre os tempos de reação médios do grupo atletas profissionais (AP) aos estímulos que ocorreram nas condições dentro e fora da moldura no Experimento II (Atenção Manifesta).

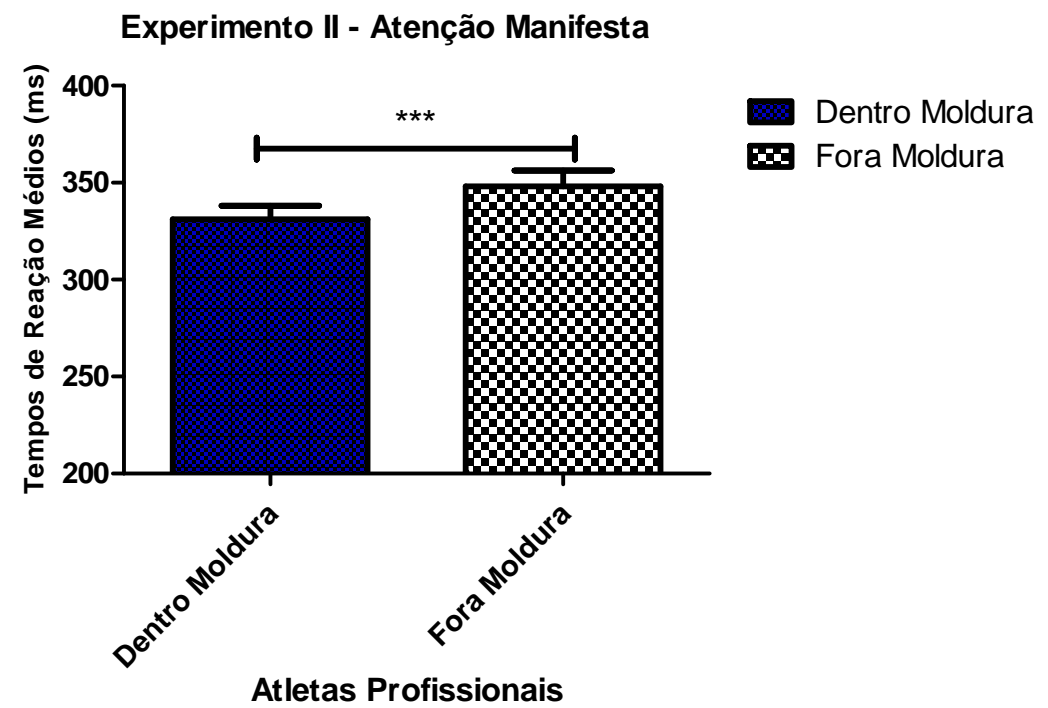

O tempo de reação médio do grupo AP aos estímulos que apareceram no interior da moldura foi $331 \mathrm{~ms}(\mathrm{EP}: \pm 7$ ms e DP: 28) e aos estímulos que apareceram fora da moldura foi de $348 \mathrm{~ms}$ (EP $\pm 8 \mathrm{~ms}$ e DP:31).

Gráfico 4 - Comparação entre os tempos de reação médios do grupo não atletas (NA) aos estímulos que ocorreram nas condições dentro e fora da moldura no Experimento II (Atenção Manifesta).

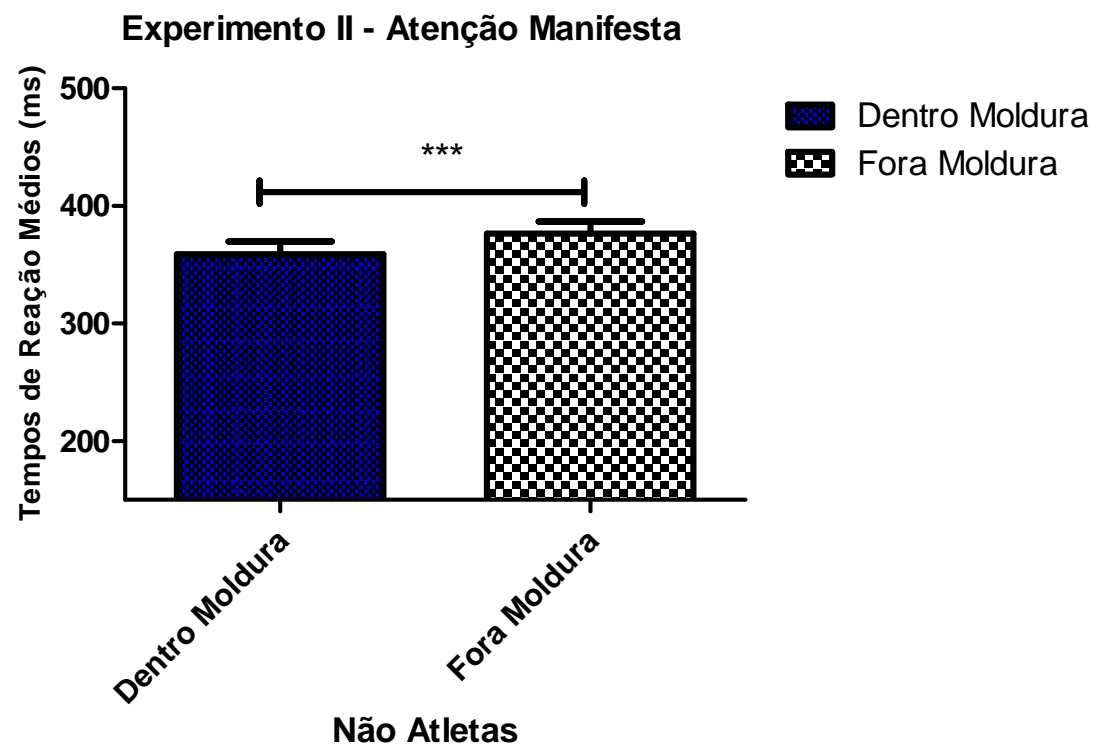

O tempo de reação médio do grupo NA aos estímulos que apareceram no interior da moldura foi $359 \mathrm{~ms}(\mathrm{EP}: \pm 11$ ms e DP:42) e aos estímulos que apareceram fora da moldura foi de $376 \mathrm{~ms}$ (EP: $\pm 10 \mathrm{~ms}$ e DP:40). 
A análise de variância (Anova Mista de Medidas Repetidas) mostrou que as diferenças entre os tempos de reação foram significativas $(p \leq 0,001)$ entre as situações dentro/fora da moldura, demonstrando o efeito da orientação da atenção, em ambos os grupos (gráficos 3, 4 e 5).

Gráfico 5 - Comparação entre os tempos de reação médios do grupo atletas (AP) e não atletas (NA) aos estímulos que ocorreram nas condições dentro e fora da moldura no Experimento II (Atenção Manifesta).

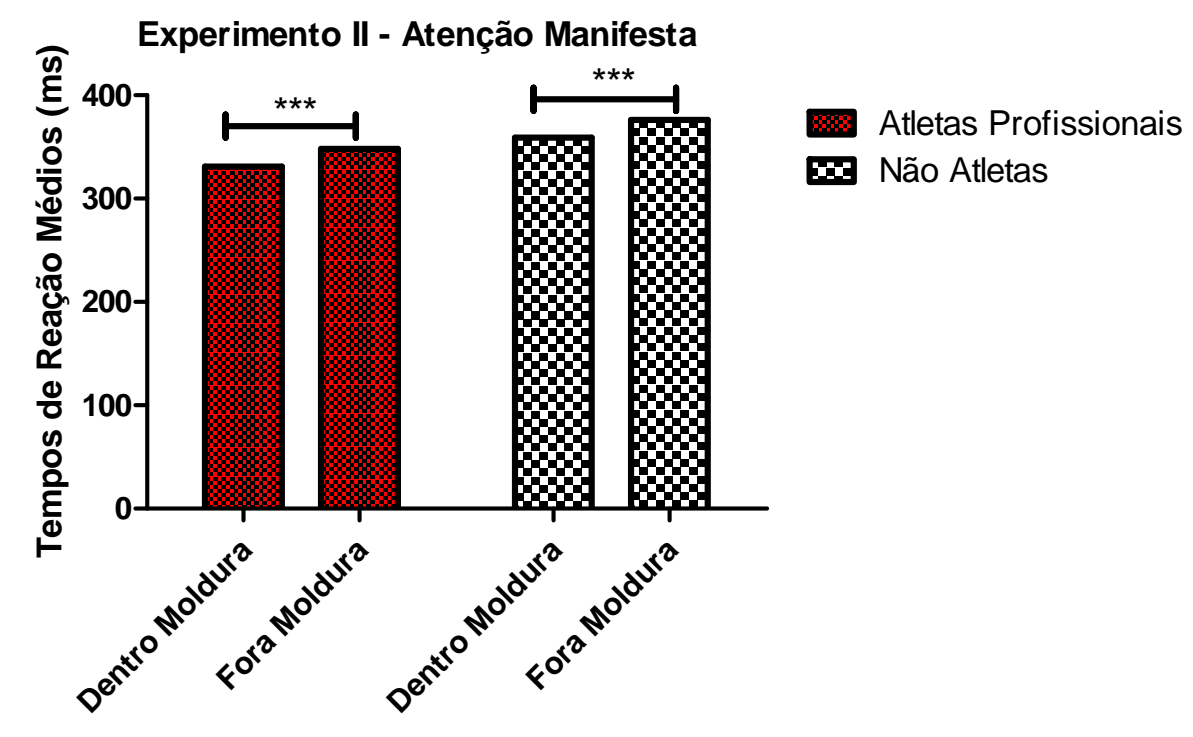

6.3 Exp III - Atenção Encoberta a esquerda

\subsubsection{Atletas Profissionais vs Não Atletas (Tempos de Reação Médios)}

Nesse experimento os estímulos foram apresentados com maior densidade no interior de uma moldura localizada do lado esquerdo da tela do monitor, favorecendo o foco atencional para aquela região. 
Gráfico 6 - Comparação entre os tempos de reação médios do grupo atletas profissionais (AP) e do grupo não atletas (NA) no Experimento III (Atenção Encoberta a Esquerda).

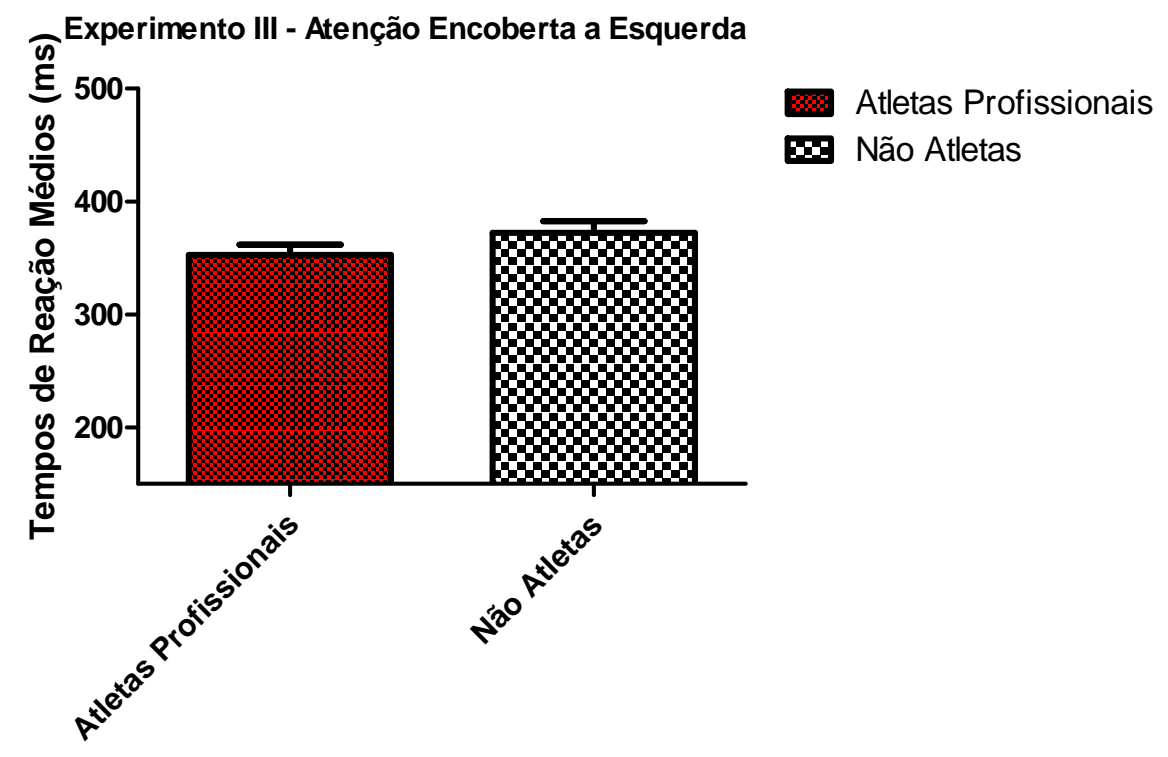

O tempo de reação médio do grupo AP foi $352 \mathrm{~ms}(\mathrm{EP}: \pm 9 \mathrm{~ms}$ e DP:35) e do grupo NA foi de $372 \mathrm{~ms}(\mathrm{EP}: \pm 10$ ms e DP:40).

Apesar das médias dos tempos de reação do grupo atletas profissionais (AP) terem sido menores do que as médias do grupo não atletas (NA) (diferença de $20 \mathrm{~ms}$ ), não foram encontradas diferenças significativas $(\mathrm{p}=0,1628)$ entre os grupos após a análise estatística (teste $t$ de Student).

\subsubsection{Orientação Voluntária da Atenção}

Em nenhum dos grupos foi demonstrado efeito da orientação voluntária da atenção para a região delimitada pela moldura. O grupo atletas profissionais (AP) apresentou tempos de reação médios discretamente menores aos estímulos que apareceram dentro da moldura em relação aos que apareceram fora da moldura (diferença de $3 \mathrm{~ms}$ ). Já o grupo não atletas (NA), apresentou tempos de reação médios discretamente maiores aos estímulos que apareceram dentro da moldura em relação aos que apareceram fora da moldura (diferença de $2 \mathrm{~ms}$ ), conforme os gráficos 7,8 e 9 . 
Gráfico 7 - Comparação entre os tempos de reação médios do grupo atletas profissionais (AP) aos estímulos que ocorreram nas condições dentro e fora da moldura no Experimento III (Atenção Encoberta a Esquerda).

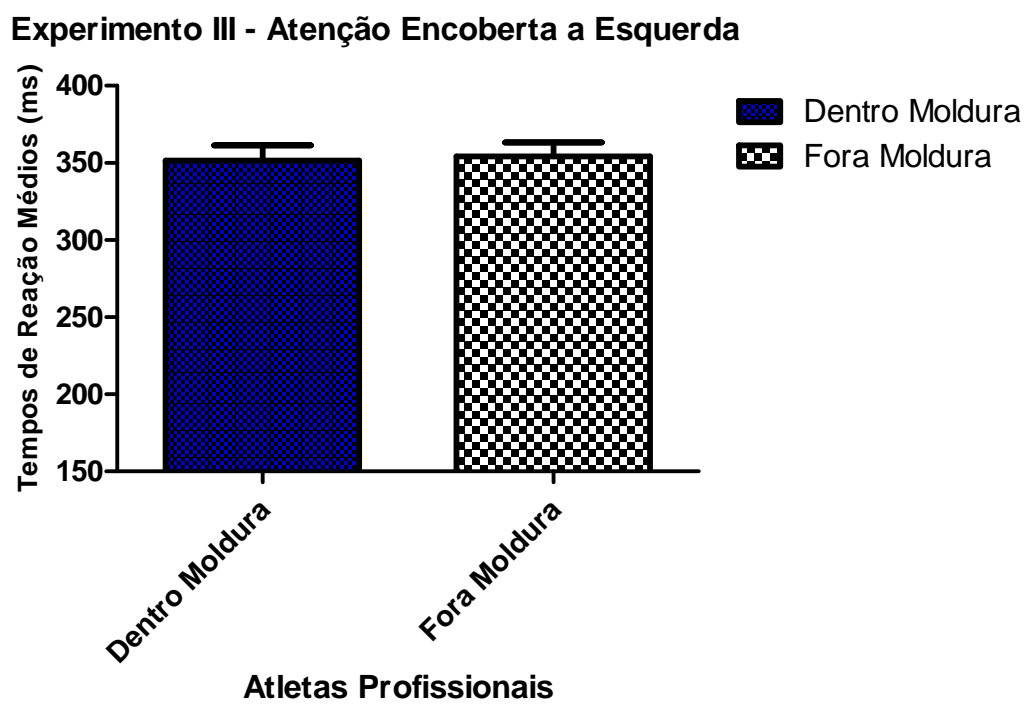

O tempo de reação médio do grupo $\mathrm{AP}$ aos estímulos que apareceram na região da moldura foi $351 \mathrm{~ms}(\mathrm{EP}: \pm 10$ ms e DP:38) e aos estímulos que apareceram fora da moldura foi $354 \mathrm{~ms}$ (EP: \pm 9 ms e DP:34).

Gráfico 8 - Comparação entre os tempos de reação médios do grupo não atletas (NA) aos estímulos que ocorreram nas condições dentro e fora da moldura no Experimento III (Atenção Encoberta a Esquerda).

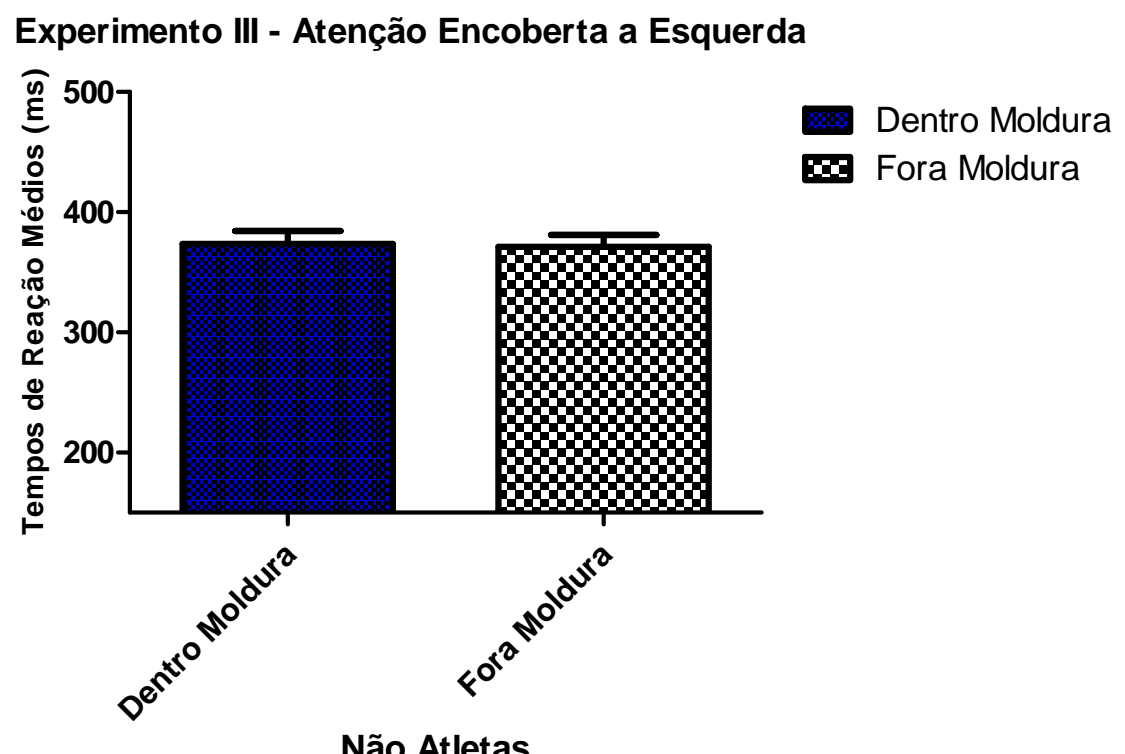

O tempo de reação médio do grupo NA aos estímulos que apareceram na região da moldura foi $374 \mathrm{~ms}(\mathrm{EP}: \pm 11$ ms e DP:41) e aos estímulos que apareceram fora da moldura foi $371 \mathrm{~ms}$ (EP: $\pm 10 \mathrm{~ms}$ e DP:38). 
Gráfico 9 - Comparação entre os tempos de reação médios do grupo atletas (AP) e não atletas (NA) aos estímulos que ocorreram nas condições dentro e fora da moldura no Experimento III (Atenção Encoberta a Esquerda).

\section{Experimento III - Atenção Encoberta a Esquerda}

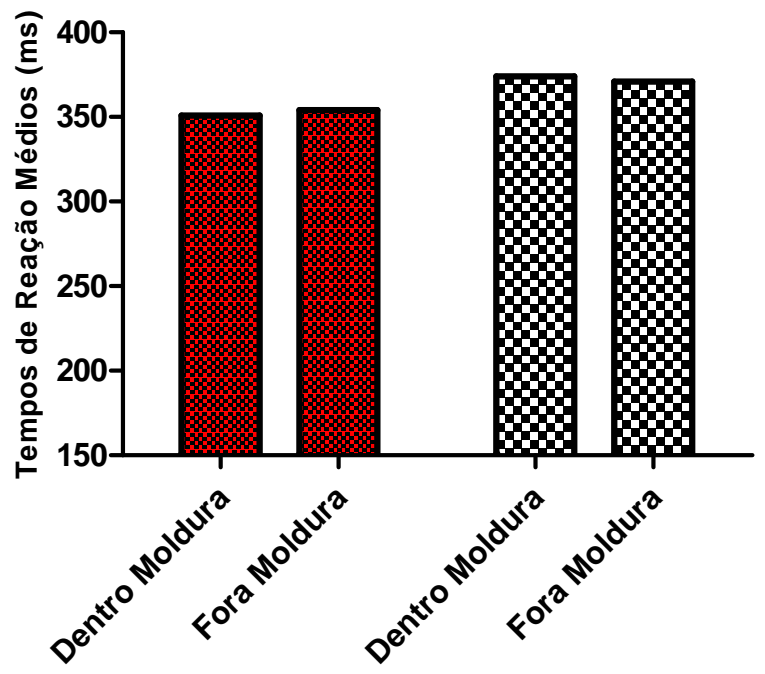

A análise de variância (Anova Mista de Medidas Repetidas) mostrou que as diferenças entre os tempos de reação não foram significativas $(p=0,8939)$ entre as situações dentro/fora da moldura, indicando que não houve efeito da orientação da atenção, em ambos os grupos.

\subsection{Exp IV - Atenção Encoberta a direita}

\subsubsection{Atletas Profissionais vs Não Atletas (Tempos de Reação Médios)}

Nesse experimento a maior densidade de estímulos ocorreu no interior de uma moldura localizada a direita da cruz de fixação. Nessa situação, os atletas profissionais (AP) apresentaram tempos de reação médios menores do que os não atletas (NA), (diferença de 26 $\mathrm{ms})$.

A análise estatística (teste $\mathrm{t}$ de Student) revelou que a diferença encontrada entre os tempos de reação médios dos grupos foi marginalmente significativa $(p=0,062)$, conforme mostra o gráfico 10. Por marginalmente significativo, entende-se um índice descritivo (p) que está próximo ao critério de significância. A transição de significativo para não significativo, segundo p ser maior ou menor que 0,05 , é uma convenção, e não corresponde a uma transição real. Valores próximos do crítico são indicativos da presença provável do efeito investigado, com uma margem de erro estimada pelo valor de $\mathrm{p}$. 
Gráfico 10 - Comparação entre os tempos de reação médios do grupo atletas profissionais (AP) e do grupo não atletas (NA) no Experimento IV (Atenção Encoberta a Direita).

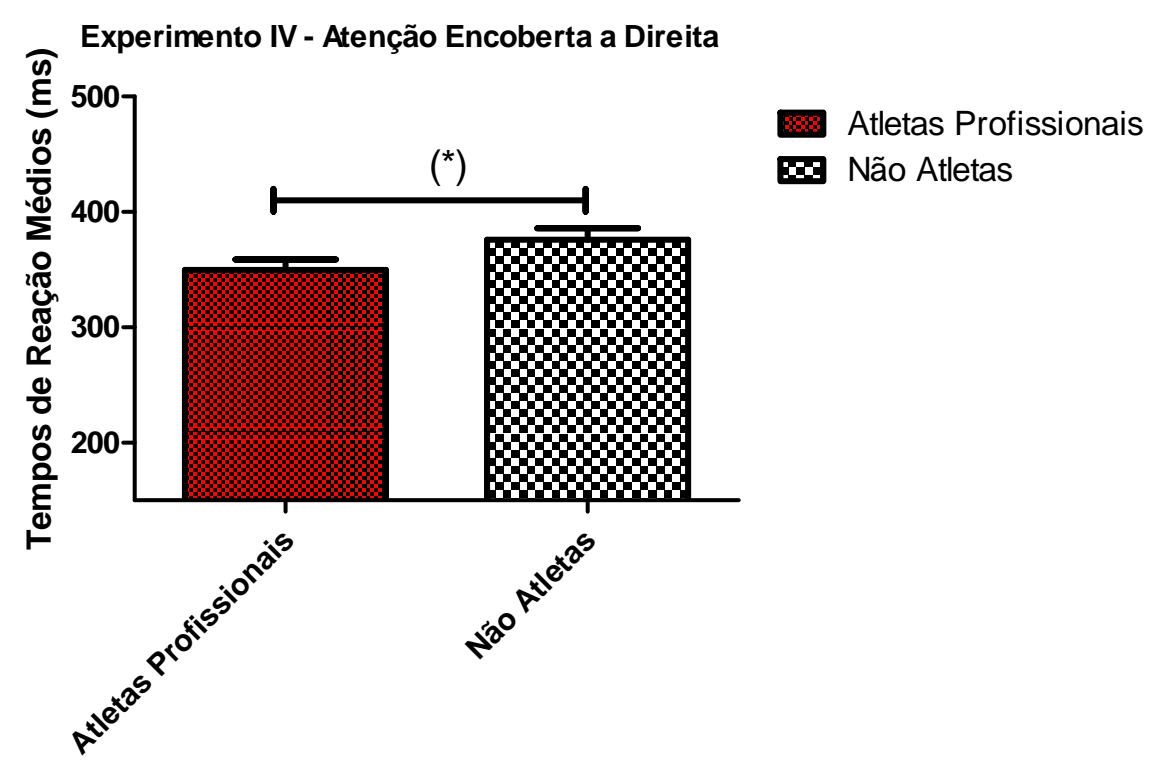

O tempo de reação médio do grupo AP foi $349 \mathrm{~ms}$ (EP: $\pm 8 \mathrm{~ms}$ e DP:34) e do grupo NA foi de $375 \mathrm{~ms}$ (EP: $\pm 9 \mathrm{~ms}$ e DP:39).

\subsubsection{Orientação Voluntária da Atenção Visual}

Em nenhum dos grupos foi demonstrado efeito da orientação voluntária da atenção para a região delimitada pela moldura (localizada a direita da tela do monitor, nesse experimento).

A exemplo dos resultados obtidos no experimento III (atenção encoberta a esquerda), o grupo atletas profissionais (AP) apresentou tempos de reação médios discretamente menores aos estímulos que apareceram dentro da moldura em relação aos que apareceram fora da moldura (diferença de $6 \mathrm{~ms}$ ). Já o grupo não atletas (NA), apresentou tempos de reação médios discretamente maiores aos estímulos que apareceram dentro da moldura em relação aos que apareceram fora a moldura (diferença de $2 \mathrm{~ms}$ ), conforme os gráficos 11, 12 e 13. 
Gráfico 11 - Comparação entre os tempos de reação médios do grupo atletas profissionais (AP) aos estímulos que ocorreram nas condições dentro e fora da moldura no Experimento IV (Atenção Encoberta a Direita).

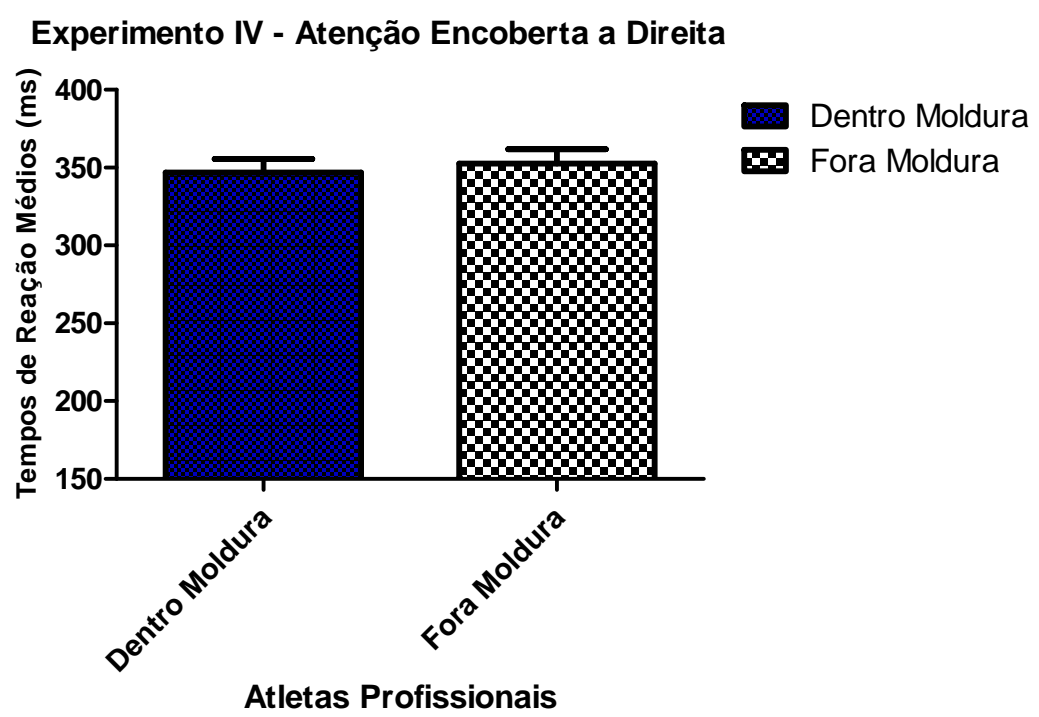

O tempo de reação médio do grupo AP aos estímulos que apareceram na região da moldura foi $347 \mathrm{~ms}(\mathrm{EP}: \pm 9$ ms e DP:34) e aos estímulos que apareceram fora da moldura foi $353 \mathrm{~ms}$ (EP: \pm 9 ms e DP:35).

Gráfico 12 - Comparação entre os tempos de reação médios do grupo não atletas (NA) aos estímulos que ocorreram nas condições dentro e fora da moldura no Experimento IV (Atenção Encoberta a Direita).

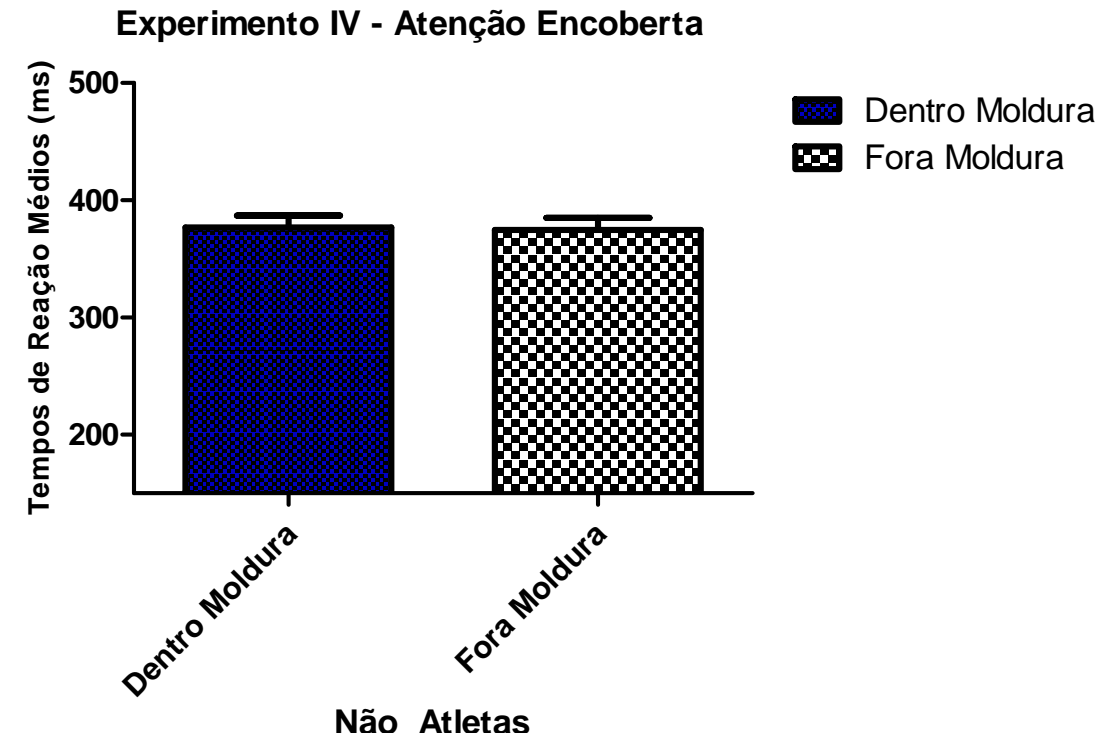

O tempo de reação médio do grupo NA aos estímulos que apareceram na região da moldura foi $377 \mathrm{~ms}(\mathrm{EP}: \pm 10$ ms e DP:39) e aos estímulos que apareceram fora da moldura foi $375 \mathrm{~ms}$ (EP: $\pm 10 \mathrm{~ms}$ e DP:39). 
Gráfico 13 - Comparação entre os tempos de reação médios do grupo atletas (AP) e não atletas (NA) aos estímulos que ocorreram nas condições dentro e fora da moldura no Experimento IV (Atenção Encoberta a Direita).

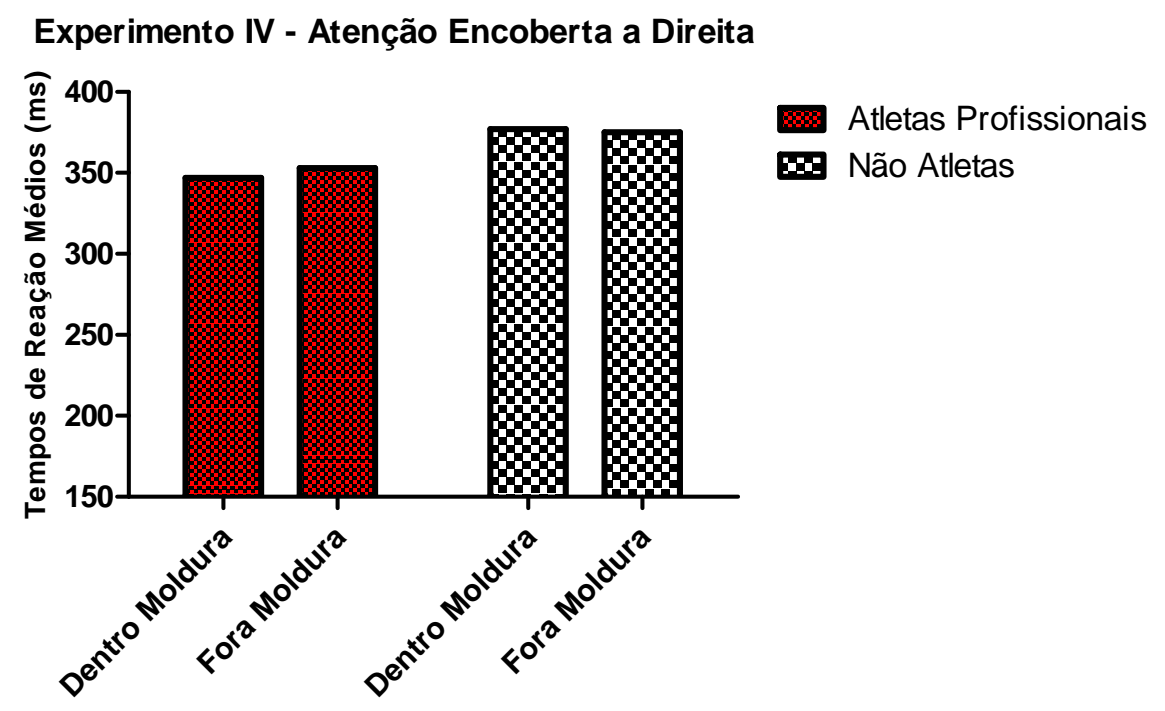

A análise de variância (Anova mista de medidas repetidas) mostrou que, diferente das outras situações experimentais, houve interação marginalmente significativa entre os grupos $(p=0,04)$. Os tempos de reação médios de ambos os grupos foram submetidos a uma nova análise (testes $\mathrm{t}$ de Student), que não mostrou diferenças significativas entre as situações dentro/fora da moldura para os grupos (AP: $p=0,12$ e NA: $p=0,25$ ).

\subsection{Experimento V - Atenção Dividida}

\subsubsection{Atletas Profissionais vs Não Atletas (Tempos de Reação Médios)}

No experimento $\mathrm{V}$ os estímulos foram apresentados com maior densidade no interior de duas molduras, presentes durante todo o experimento (a direita e a esquerda do ponto de fixação), induzindo a divisão do foco atencional em dois. O grupo atletas profissionais (AP) apresentou tempos de reação médios mais curtos do que o grupo não atletas (NA) e a diferença entre os grupos foi significativa $(p \leq 0,04)$ após a realização do teste estatístico ( $\mathrm{t}$ de Student) - gráfico 14. 
Gráfico 14 - Comparação entre os tempos de reação médios do grupo atletas profissionais (AP) e do grupo não atletas (NA) no Experimento V (Atenção Dividida).

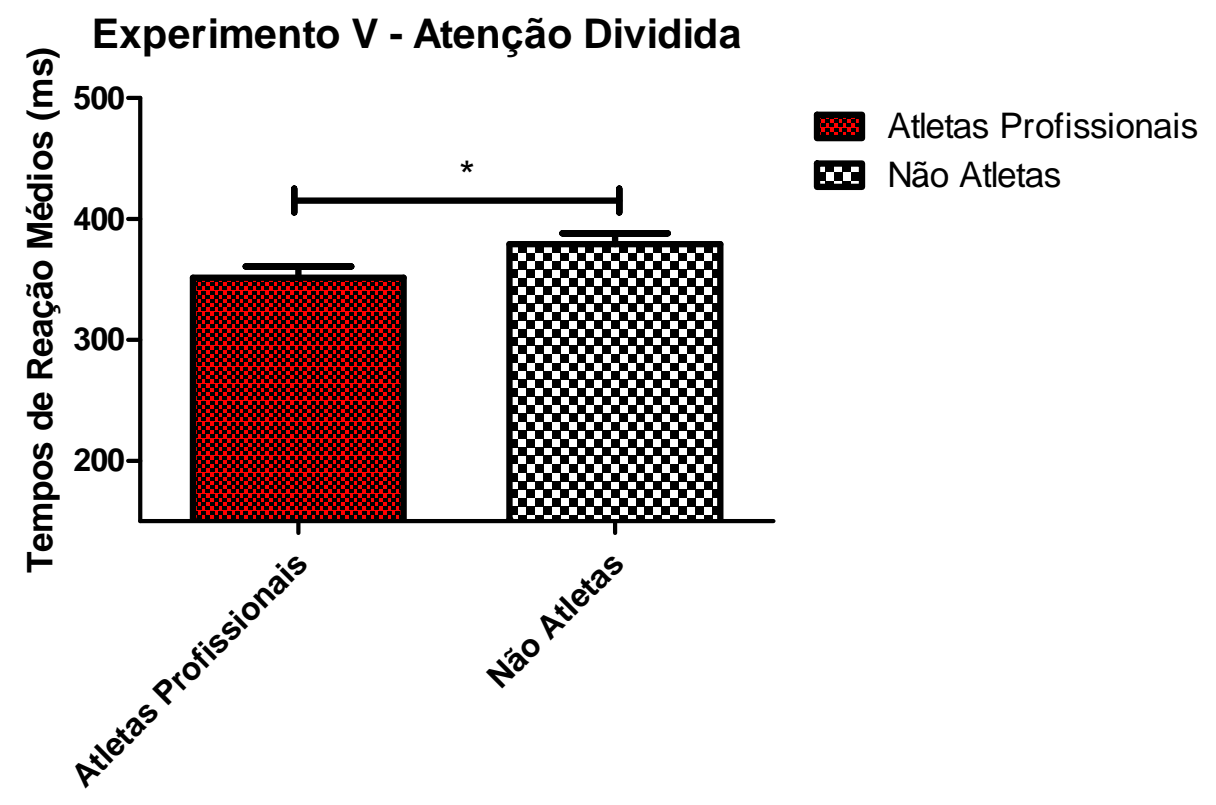

O tempo de reação médio do grupo AP foi $351 \mathrm{~ms}$ (EP: \pm 9 ms e DP:36) e do grupo NA foi $379 \mathrm{~ms}$ (EP: $\pm 9 \mathrm{~ms}$ e DP:35).

\subsubsection{Orientação Voluntária da Atenção Visual}

Em nenhum dos grupos foi demonstrado efeito da orientação voluntária da atenção para a região delimitada pelas molduras (localizadas a esquerda e a direita da tela do monitor). 
Gráfico 15 - Comparação entre os tempos de reação médios do grupo atletas profissionais (AP) aos estímulos que ocorreram nas condições fora da moldura, dentro da moldura 1 (a esquerda) e dentro da moldura 2 (a direita) no Experimento V (Atenção Dividida).

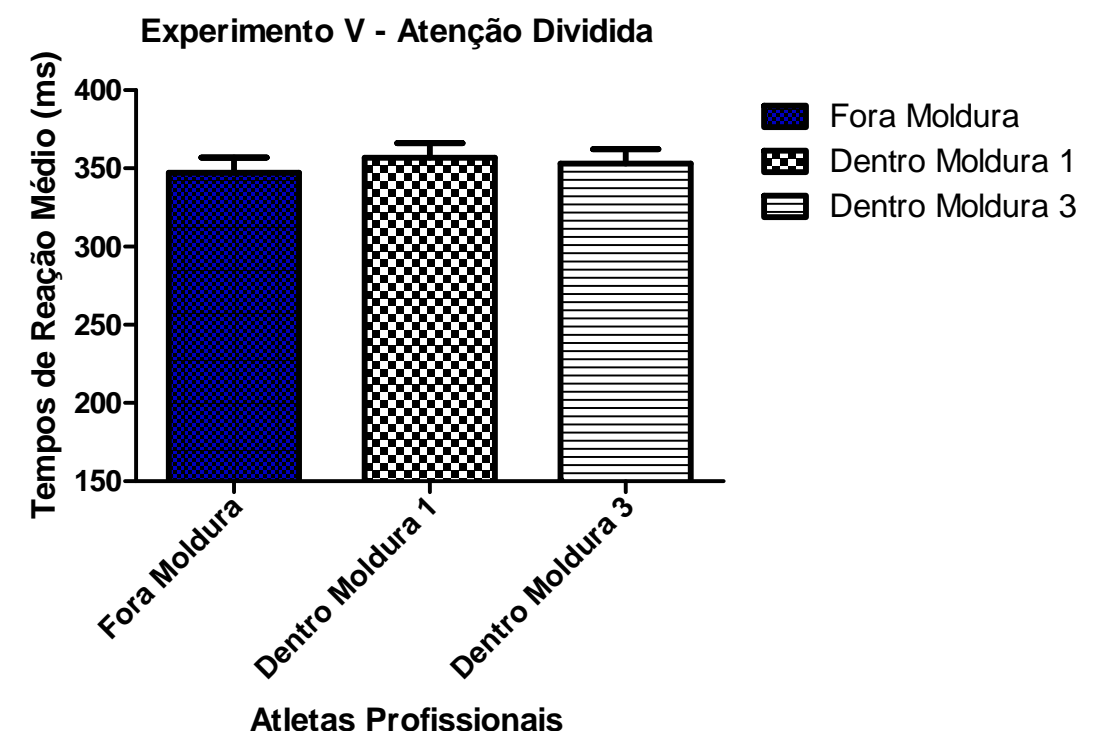

O tempo de reação médio do grupo AP aos estímulos que apareceram na região da moldura 1 foi $357 \mathrm{~ms}(\mathrm{EP}: \pm 9$ ms e DP:36), na região da moldura 2 foi 353 ms (EP: \pm 9 ms e DP:36) e aos estímulos que apareceram fora da moldura foi $347 \mathrm{~ms}(\mathrm{EP}: \pm 10 \mathrm{~ms}$ e DP:38).

Gráfico 16 - Comparação entre os tempos de reação médios do grupo não atletas (NA) aos estímulos que ocorreram nas condições fora da moldura e dentro da moldura 1 (a esquerda) e 2 (a direita) no Experimento V (Atenção Dividida).

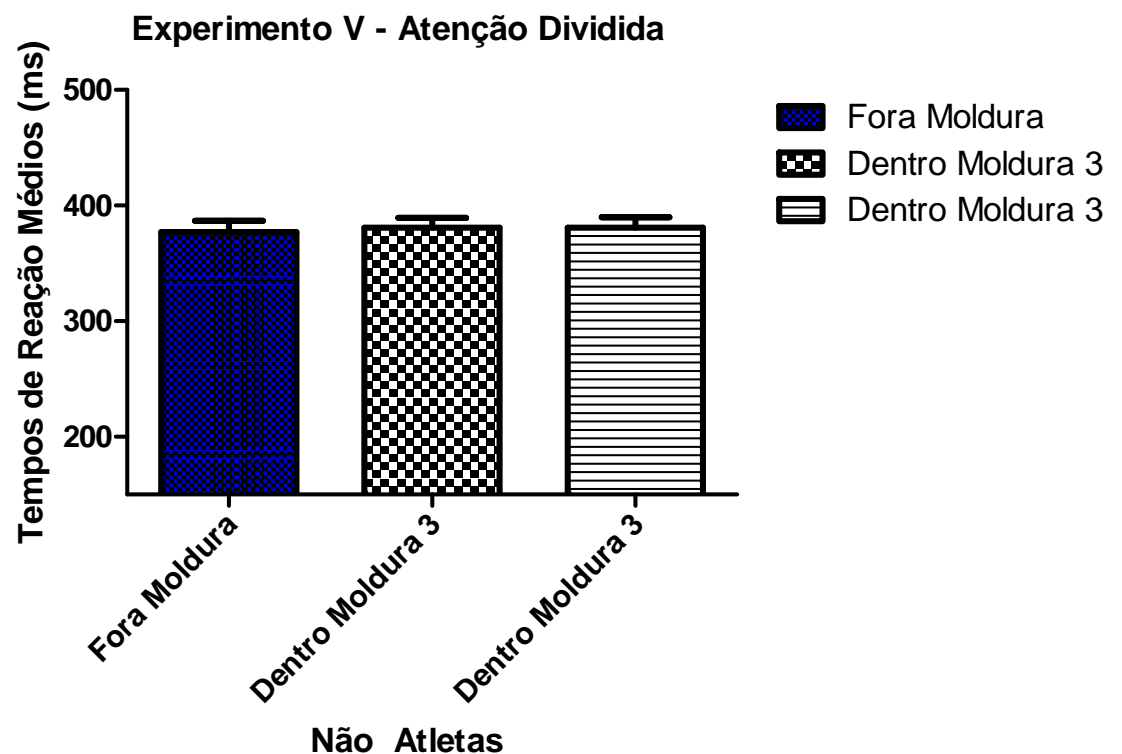

O tempo de reação médio do grupo AP aos estímulos que apareceram na região da moldura 1 foi $381 \mathrm{~ms}(\mathrm{EP}: \pm 8$ ms e DP:33), na região da moldura 2 foi $381 \mathrm{~ms}$ (EP: $\pm 9 \mathrm{~ms}$ e DP:35) e aos estímulos que apareceram fora da moldura foi $377 \mathrm{~ms}(\mathrm{EP}: \pm 10 \mathrm{~ms}$ e DP:38). 
Gráfico 17 - Comparação entre os tempos de reação médios do grupo atletas (AP) e não atletas (NA) aos estímulos que ocorreram nas condições fora da moldura, dentro da moldura 1 (a direita) e dentro da moldura 2 (a esquerda) no Experimento V (Atenção Dividida)

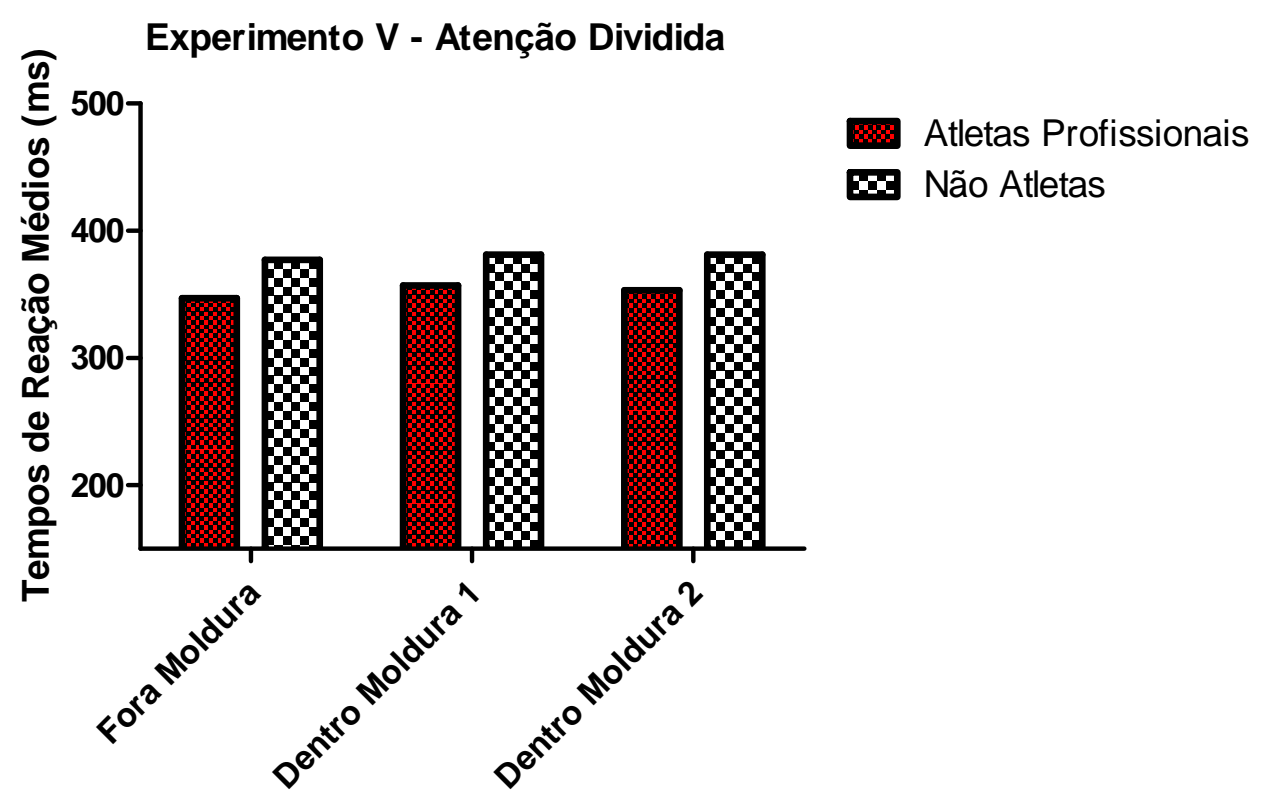

Ambos os grupos apresentaram resultados semelhantes: o grupo atletas profissionais (AP) apresentou tempos de reação médios discretamente maiores aos estímulos que apareceram dentro da moldura em relação aos que apareceram fora da moldura (diferença de $10 \mathrm{~ms}$ em relação a moldura 1 e diferença de $6 \mathrm{~ms}$ em relação a moldura 2). Já o grupo não atletas (NA) também apresentou tempos de reação médios discretamente maiores aos estímulos que apareceram dentro das molduras (diferença de $4 \mathrm{~ms}$ para as molduras 1 e 2), conforme os gráficos 15,16 e 17. 


\section{DISCUSSÃO GERAL}

7.1 Atletas Profissionais vs Não Atletas (Tempos de Reação Médios)

Confirmando os achados de Vaghetti et al., (2007), Carreiro et al., (2009) e Gunthla et al., (2012), o grupo atletas profissionais (AP) apresentou tempos de reação (médios) menores do que o grupo não atletas (NA) em todas as situações experimentais (experimentos de I a V), conforme mostram o gráfico 18 e o quadro 1.

Gráfico 18 - Comparação entre os tempos de reação médios dos grupos atletas profissionais (AP) e não atletas (NA) nas cinco condições experimentais.

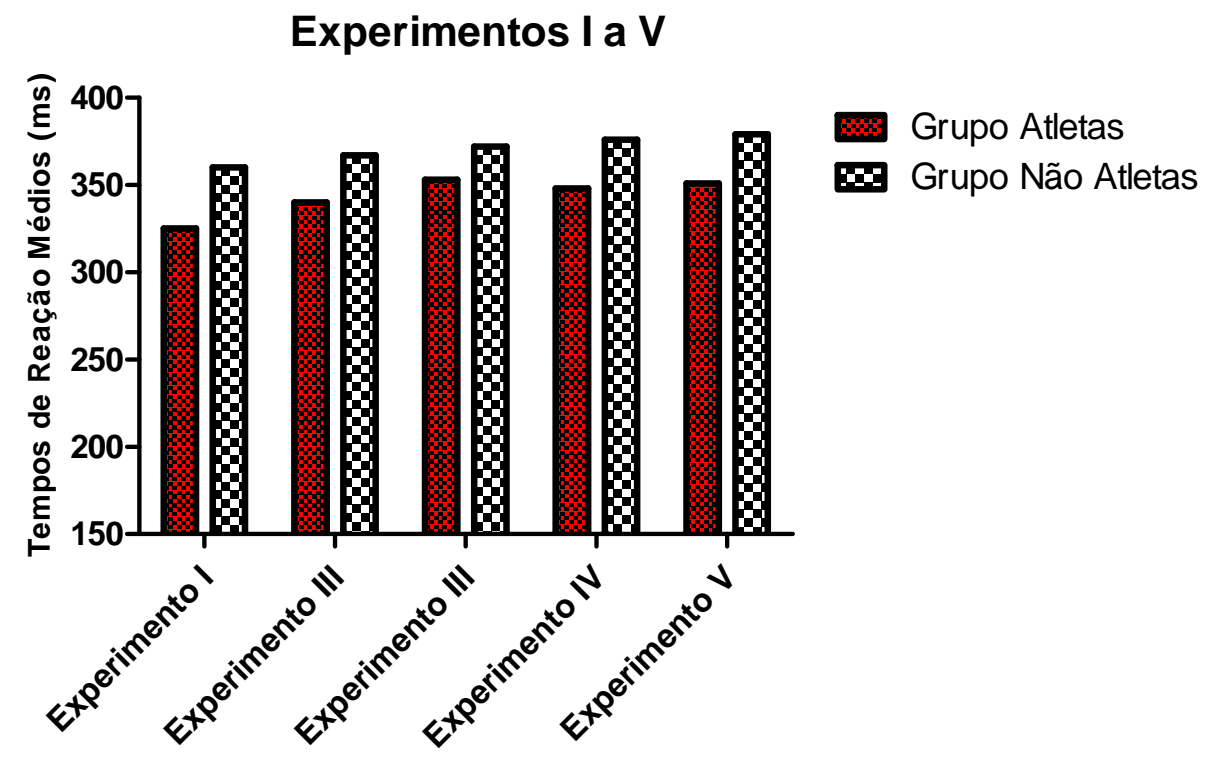

Quadro 1 - Tempos de reação médios do grupo atletas profissionais (AP ) e não atletas (NA) em todas as situações experimentais (experimentos de I a V).

\begin{tabular}{|l|l|l|}
\hline & $\begin{array}{l}\text { Grupo Atletas } \\
\text { Profissionais }\end{array}$ & $\begin{array}{l}\text { Grupo Não } \\
\text { Atletas }\end{array}$ \\
\hline Experimento I & $325 \mathrm{~ms}$ & $360 \mathrm{~ms}$ \\
\hline Experimento II & $340 \mathrm{~ms}$ & $367 \mathrm{~ms}$ \\
\hline Experimento III & $353 \mathrm{~ms}$ & $372 \mathrm{~ms}$ \\
\hline Experimento IV & $348 \mathrm{~ms}$ & $376 \mathrm{~ms}$ \\
\hline Experimento V & $351 \mathrm{~ms}$ & $379 \mathrm{~ms}$ \\
\hline
\end{tabular}


As diferenças entre os grupos foram significativas $(p \leq 0,05)$ nos experimentos I (atenção difusa, com diferença de $35 \mathrm{~ms}$ ), II (atenção manifesta, com diferença de $27 \mathrm{~ms}$ ), IV (atenção encoberta a direita, com diferença de $28 \mathrm{~ms}$, situação em que as diferenças entre os grupos foram marginalmente significativas, $\mathrm{p}=0,062$ ) e V (atenção dividida, com diferença de $28 \mathrm{~ms}$ ).

No experimento III (atenção encoberta a esquerda), as diferenças entre os grupos não foram significativas $(\mathrm{p}=0,1628)$, apesar do grupo atletas profissionais (AP) ter sido novamente mais rápido (diferença de $19 \mathrm{~ms}$ ).

7.2 Orientação Voluntária da Atenção Visual

O grupo atletas profissionais (AP) não apresentou diferenças significativas no que diz respeito à orientação voluntária da atenção em relação ao grupo não atletas (NA). Porém, apesar das diferenças não serem significativas, o grupo de atletas profissionais demonstrou maiores benefícios da orientação da atenção (tempos de reação aos estímulos que apareceram no interior das regiões delimitadas pelas molduras menores do que nas demais regiões), na maioria das situações experimentais (experimentos II, III e IV), conforme mostrado nas figuras 16 e 17 . 
Figura 16 - Tempos de reação médios (TR Médio) aos estímulos visuais que apareceram dentro e fora da moldura em cada condição experimental (experimentos II a $\mathrm{V})$, para o grupo atletas profissionais (AP).

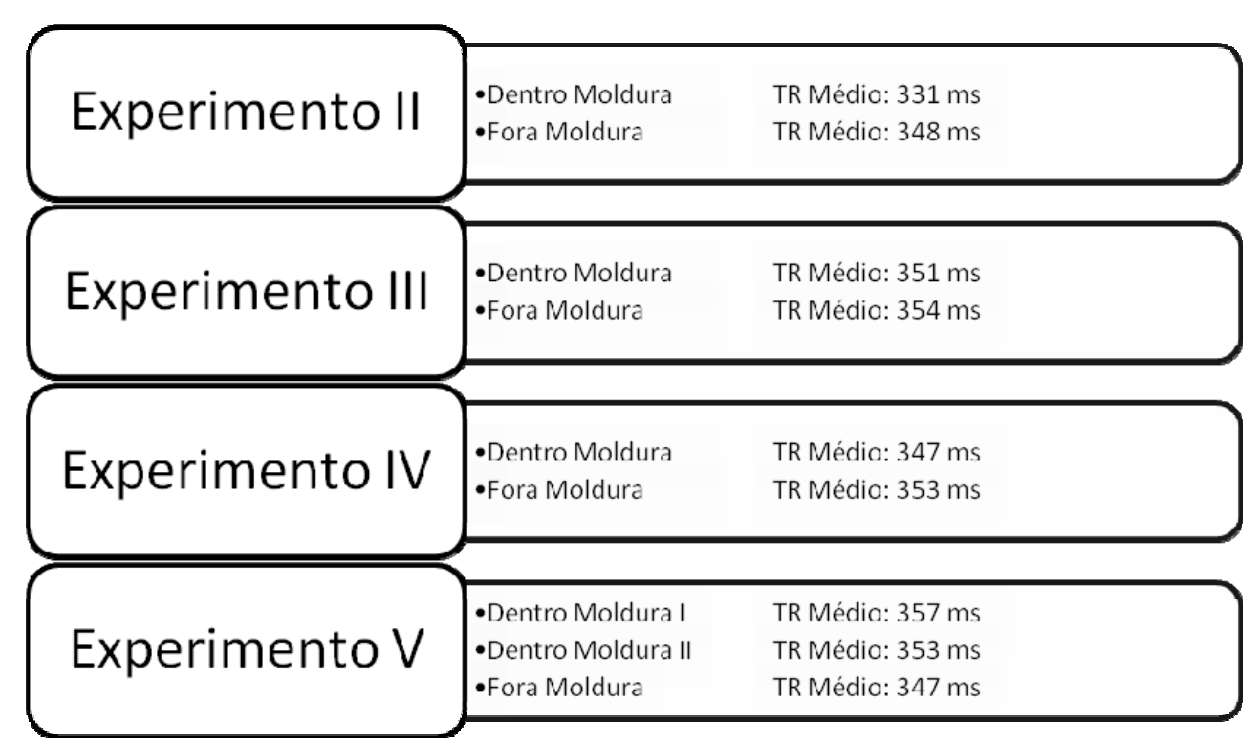

Figura 17 - Tempos de reação médios (TR Médio) aos estímulos visuais que apareceram dentro e fora da moldura em cada condição experimental (experimentos II a $\mathrm{V})$, para o grupo não atletas (NA).

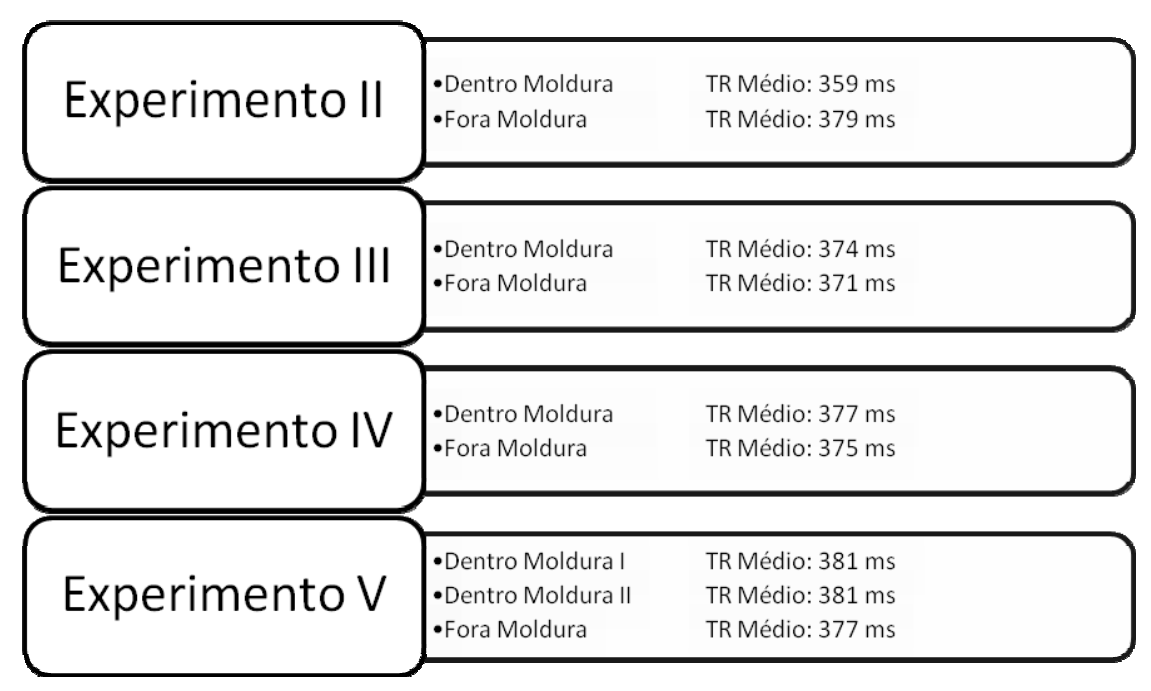

No experimento II (Atenção Manifesta), as diferenças entre as condições dentro/fora da moldura de ambos os grupos foi a mesma (17 ms), com claro favorecimento para a região da moldura, para onde houve orientação voluntária da atenção visual. Já no experimento III (atenção encoberta a esquerda) e IV (atenção encoberta a direita), os atletas profissionais apresentaram tempos de reação médios discretamente menores aos estímulos que apareceram dentro da moldura do que aos estímulos que apareceram nas regiões além da moldura 
(diferença de $3 \mathrm{~ms}$ no experimento III e diferença de $4 \mathrm{~ms}$ no experimento IV), enquanto o grupo dos voluntários não atletas demonstrou o comportamento contrário: os tempos de reação médios aos estimulo que ocorreram dentro das molduras foram discretamente maiores (diferença de $3 \mathrm{~ms}$ no Experimento III e diferença de $2 \mathrm{~ms}$ no experimento IV) do que os tempos de reação médios aos estímulos que ocorreram nas demais regiões, fora das molduras.

Esses resultados parecem demonstrar que, apesar das diferenças entre os grupos não terem sido significativas, os atletas apresentaram discretos benefícios na orientação da atenção, traduzidos por pequenas diferenças entre os tempos de reação médios aos estímulos que ocorreram dentro e fora das regiões das molduras, comportamento não observado no grupo não atletas, em ambos os experimentos (III e IV).

Os resultados obtidos não confirmam as evidências encontradas por alguns pesquisadores (CASTIELLO; UMILTA, 1992; NOUGIER; RIPOLL; STEIN, 1989; NOUGIER; AZEMAR; STEIN, 1992), de que atletas experientes apresentariam menores efeitos da orientação voluntária do que não atletas. A hipótese levantada pelos autores seria que atletas seriam capazes de alterar o local de atenção mais rapidamente do que não atletas, não apresentando grande dependência de dicas externas. Tal argumento requer futuras investigações para ser confirmado.

Uma hipótese para a ocorrência desses resultados seria a de que atletas experientes possuem um processamento mais eficiente dos estímulos que aparecem no campo visual, tanto nas regiões esperadas quanto nas regiões inesperadas.

Já no experimento V (atenção dividida), ambos os grupos apresentaram tempos de reação médios discretamente maiores aos estímulos que ocorreram dentro das regiões das molduras ( 1 e 2 , localizadas a esquerda e a direita na tela do monitor, respectivamente) do que aos estímulos que apareceram fora das molduras. Esses resultados parecem demonstrar que a tarefa de dividir a atenção para as regiões das molduras não foi eficiente, para ambos os grupos. No caso dos atletas, a dificuldade apresentada na situação de atenção dividida foi mais notável, pois essa foi a única situação experimental em que o grupo atletas apresentou tempos de reação médios aos estímulos que apareceram dentro das molduras discretamente maiores do que os tempos de reação médios aos estímulos que apareceram fora das regiões das molduras.

As diferenças entre as situações dentro e fora da moldura não foram significativas em nenhum experimento, em ambos os grupos, com exceção do experimento II (Atenção Manifesta). Nessa situação experimental, quando a maior densidade dos estímulos ocorreu no interior de uma moldura localizada no centro da tela do computador, ao redor da cruz de 
fixação, ambos os grupos apresentaram tempos de reação médios significativamente $(\mathrm{p} \leq 0,05)$ mais curtos aos estímulos que apareceram dentro da região delimitada pela moldura do que aos estímulos que apareceram fora da região da moldura, demonstrando maior eficiência na orientação da atenção para o local.

Os resultados encontrados no experimento II (Atenção Manifesta) condizem com as evidências de Araújo e Carreiro (2009), Posner (1978) e Posner (1980), de que os tempos de reação a estímulos que aparecem nos locais para onde a atenção é orientada são mais curtos do que os tempos de reação aos estímulos que aparecem em outras regiões do campo visual. Estes resultados, porém, podem simplesmente decorrer das características da anatomia e da fisiologia ocular: maior densidade de fotorreceptores na região central do campo visual, que incide no centro da retina (fóvea), região que permite a percepção de detalhes finos do estímulo visual (OYSTER, 1999; WRIGHT; LAWRENCE, 2008).

Já nos demais experimentos (III - Atenção Encoberta a Esquerda; IV - Atenção Encoberta a Direita e V - Atenção Dividida), não foram encontradas diferenças significativas entre as condições dentro/fora das molduras, contrariando os achados de outros pesquisadores do nosso laboratório (AZEVEDO, 2009; CANTO-PEREIRA et al., 2005, 2006), que mostraram um claro e bem definido holofote atencional na região para onde a atenção havia sido orientada, nas mesmas situações experimentais realizadas neste estudo (exceto pelo grupo estudado, que era formado por indivíduos da população em geral), inclusive na situação de atenção dividida.

Acreditamos que os resultados anteriormente obtidos em nosso laboratório não foram aqui reproduzidos devido a pequenas diferenças na metodologia experimental.

O grupo experimental do presente estudo foi formado apenas por indivíduos do sexo masculino: atletas profissionais de futebol de campo, grupo que não foi estudado nos trabalhos anteriores. O grupo controle foi formado por voluntários não atletas, com pelo menos 3 anos de sedentarismo. Os trabalhos anteriores utilizaram apenas um grupo experimental, formado por voluntários de ambos os sexos e que não faziam parte de nenhum grupo específico (atletas ou não atletas).

Outra hipótese para a ocorrência dos resultados discrepantes pode ser a ocorrência de pequenas diferenças nas instruções experimentais e na forma como os grupos interpretaram essas instruções.

No presente trabalho foi solicitado que os voluntários apertassem o botão do joystick o mais rápido possível em resposta ao aparecimento dos estímulos visuais, em todas as situações experimentais. Nos experimentos onde haviam molduras (II, III, IV e V), houve a 
informação adicional de que os estímulos apareceriam mais vezes nas regiões dentro das molduras, induzindo que os voluntários prestassem atenção naquela região. Já nos experimentos anteriores realizados em nosso laboratório foi solicitado explicitamente que os voluntários prestassem atenção às áreas delimitadas pelas molduras, justificando o fato da densidade de estímulos ser maior naquelas regiões do que no resto da tela do computador.

Os atletas, mais competitivos por natureza, podem ter se sentido mais motivados a desempenhar a tarefa de uma forma mais rápida e eficiente, demonstrando maior rapidez em todas as condições experimentais e maiores vantagens na orientação encoberta da atenção.

Alternativamente, outra hipótese é de que as prováveis melhores condições de saúde e eficiência cardiovascular sejam a causa do melhor desempenho. O benefício do exercício no desempenho de tarefas cognitivas é bem documentado na literatura, conforme exposto por Etnier et al., (1997) e Ghuntla et al., (2012). 


\section{CONCLUSÃO}

O grupo atletas profissionais (AP) apresentou tempos de reação mais curtos do que o grupo não atletas (NA) em todos os experimentos, confirmando os achados de Carreiro, Ferreira e Machado-Pinheiro (2009), Gunthla et al. (2012) e Vaghetti et al. (2007).

Vários fatores poderiam explicar o melhor desempenho do grupo atletas profissionais. Talvez seja uma questão de traço de personalidade, ligado à grande motivação na excelência em qualquer tarefa do atleta de alto rendimento. Por outro lado, poderia ser o resultado de uma melhor condição física, com alta eficiência cardiovascular, garantindo uma melhor irrigação cerebral (ETNIER et al., 1997; GHUNTLA et al., 2012). Ainda, o treinamento ao qual os atletas são submetidos poderia melhorar os tempo de reação na identificação dos estímulos (CARREIRO; FERREIRA; MACHADO-PINHEIRO, 2009). Apenas estudos ulteriores, longitudinais, poderão esclarecer esse questão de uma forma mais definitiva.

Os atletas experientes não diferiram dos não atletas nas tarefas de atenção encoberta (a direita e a esquerda) e de divisão da atenção. Esse resultado é compatível com os achados de Abernethy, Neal e Koning, (1994) e Memmert, Simons e Grimme, (2009), mas contrariam os de Carreiro, Ferreira e Machado-Pinheiro (2009), Cereatti et al., (2008) e Enns e James (1997). O fato de haver na literatura relatos aparentemente contraditórios pode ser conseqüência de detalhes na situação experimental. No nosso próprio laboratório foram obtidos resultados muito mais claros dos aqui apresentados, mostrando tempos de reação significativamente mais curtos dentro das molduras do que fora, resultado provavelmente ligado a instruções mais explícitas quanto ao orientar a atenção para as regiões demarcadas pelas molduras.

Concluímos que experimentos de atenção visual que adotem protocolos semelhantes ao utilizado no presente trabalho sejam executados com muita atenção quanto às instruções fornecidas aos voluntários. 


\section{REFERÊNCIAS*}

ANDO, S.; KIDA, N.; ODA, S. Central and peripheral visual reaction time of soccer players and nonathletes. Perceptual and Motor Skills, v. 92, p. 786-794, 2001.

ABERNETHY, B. Visual search strategies and decision-making in sports. International Journal of Sports Psychology, v. 22, p. 189-210, 1992.

ABERNETHY, B.; NEAL, R. J.; KONING, P. Visual-perceptual and cognitive differences between expert, intermediate and novice snooker players. Applied Cognitive Psychology, v. 18, p. 185-211, 1994.

ARAUJO, R. R.; CARREIRO, L. R. R. Orientação voluntária e automática da atenção e indicadores de desatenção e hiperatividade em adultos. Avaliação Psicológica, v. 8, n. 3, p. 325-336, 2009.

AZEVEDO, A. M. S. Mapeamento espacial da atenção visual mobilizada pela via visual ventral. 2009. 53 f. Dissertação (Mestrado em Fisiologia Humana) - Instituto de Ciências Biomédicas, Universidade de São Paulo, São Paulo, 2009.

AWH, E.; PASHLER, H. Evidence for split attentional foci. Journal of Experimental Psychology Human Perception Performance, v. 26, n. 2, p. 834-846, 2006.

BERNE, R. M.; LEVY, M. M.; KOEPPEN, B. M.; STANTON, B.A. Fisiologia. 6. ed. Rio de Janeiro: Elsevier, 2009.

CANTO-PEREIRA, L. H. M. Mapeamento espacial da atenção visual através de tempos de reação: um estudo psicofísico. 2006. 92 f. Dissertação (Doutorado em Neurociências e Comportamento) - Instituto de Psicologia, Universidade de São Paulo, São Paulo, 2006.

CANTO-PEREIRA, L. H. M.; RANVAUD, R.; DIAS, H. S. A geostatistical approach to asses the spatial distribution of visual attention. Investigative Ophtalmology \& Visual Science, 46 E, 2005.

CARREIRO, L. R. R.; FERREIRA, I. R.; MACHADO-PINHEIRO, W. Comparação de desempenho de jogadores de voleibol e não esportistas em tarefas de orientação automática e voluntária da atenção visual: um estudo exploratório. Psicologia: Teoria e Prática, v. 11, n. 2, p. 38-49, 2009.

CASTIELLO, U.; UMILTA, C. Orienting of attention in volleyball players. International Journal of Sports Psychology, v. 23, p. 301-310, 1992.

CAVANAGH, M. C.; ALVAREZ, G. A. Tracking multiple targets with multifocal attention. Trends in Cognitive Sciences, v. 9, n. 7, p. 349-354, 2005.

\footnotetext{
* De acordo com:

ASSOCIAÇÃO BRASILEIRA DE NORMAS TÉCNICAS. NBR 6023: informação e documentação: referências: elaboração. Rio de Janeiro, 2002.
} 
CEREATTI, L.; CASELLA, R.; MANGANELLI, M.; PESCE, C. Visual attention in adolescents: facilitating effects of sports expertise and acute physical exercise. Psychology of Sports and Exercise, v.10, p. 136-145, 2008.

DOWNING, C. J.; PINKER, S. The spatial structure of visual attention. In: POSNER, M. I.; MARIN, O. S. (Ed.). Attention and performance XI: mechanisms of attention. Hillsdale: Eribaum, 1985. p. 675.

ENNS, J. T. E.; RICHARDS, J. C. Visual orienting in developing hockey players. Journal of Experimental Child Pshychology, v. 64, p. 255-275, 1997.

ERIKSEN, C. W., ST JAMES, J. D. Visual attention within and around the field of focal attention: a zoom lens model. Perception and Psychopysics, v. 40, p. 225-240, 1986.

ETNIER, J. L.; SALAZAR, W.; LANDERS, D. M.; PETRUZZELLO, S. J.; HAN, M.; NOWELL, P. The influence of psysical fitness and exercise upon cognitive functioning: a meta-analysis. Journal of Sports \& Exercise Psychology, v. 19, p. 249-277, 1997.

GAZZANIGA, M. S.; IVRY, R. B.; MANGUN, G. R. Neurociência cognitiva: a biologia da mente. 2. ed. Porto Alegre: Artmed, 2006.

GHUNTLA, T. P.; MEHTA, H. B.; GOKHALE, P. A.; SHAH, C. J. A comparative study of visual reaction time in basketball players and healthy controls. National Journal of Integrated Research in Medicine, v. 3, n. 1, p. 49-51, 2012.

GRAPHPAD PRISM. Version 5.00.288. EUA: GraphPad Software, Inc.

GUIZANI, S. M.; BOUZAOUACG, I.; TENENBAUM, G.; BEM KHEDER, A.; FEKI, Y.; BOUAZIZ, M. Simple and choice reaction times under varying levels of physical load in high skilled fencers. The Journal of Sports Medicine and Physical Fitness, v. 46, p. 344-351, 2006.

ITU-GAZE TRACKER. Denmark: IT University of Copenhagen. Open Source Software. Available from: $<$ http://www.gazegroup.org $>$.

IVYROSE HOLISTIC. Diagrama de formação de imagens no olho. 2012. Disponível em: $<$ http://www.ivy-rose.co.uk/HumanBody/Eye/Eye_Image-Formation.php >. Acesso em $12 \mathrm{de}$ março de 2012.

JAKOBS, O.; WANG, L. E.; DAFOTAKIS, M.; GREFKES, C.; ZILLES, K.; EICKHOFF, S. B. Effects of timing and movement uncertainty implicate the temporo-parietal junction in the prediction of forthcoming motor actions. NeuroImage, v. 47, n.2, p. 667-677.

JOURNEL, A. G. Geostatics: models and tools for the earth sciences. Math. Geol., v. 18, p. 119-140, 1979.

KRAFT, A.; MULLER, N. G.; HAGENDORF, H.; SCHIRA, M. M.; DICK, S.; FRENDRICH, R. M.; BRANDT, S. A. Interactions Between task difficulty and hemispheric 
distribution of attended locations: implications for the splitting attention debate. Cognitive Brain Research, v. 24, p. 19-32, 2005.

MATLAB. Version 7.8.0.347. EUA: MathWorks. Software.

MEMMERT, D.; SIMONS, D. J.; GRIMME, T. The relationship between visual attention and expertise in sports. Psychology of Sport and Exercise, v. 10, p. 146-152, 2009.

MULlER, N. G., BARTELT, O. A., DONNER, T. H., VILLRINGER, A. BRANDT, S. A. A physiological correlate of the "lens zoon" of visual attention. The Journal of Neuroscience, v. 23, pt. 9, p. 3561-3565, 2003.

LABERGE, D. Attentional processing: the brain's art of mindfulness. Perspectives in congnitive neuroscience. Cambridge, MA: Harvard University Press, 1995.

NOUGIER, V.; RIPOLL, H.; STEIN, J. F. Orienting attention with highly skilled athletes. International Journal of Sport Psychology, v. 20, p. 205-223, 1989.

NOUGIER, V.; AZEMAR, G.; STEIN, J. F. Cover orienting to central visual cues and sport practice relations in the development of visual attention. Journal of Experimental Child Psychology, v. 54, p. 315-333, 1992.

OLDFIELD, R. C. The assessment and analysis of handedness: the Edinburgh inventory. Neuropychology, v. 9, p. 97-113, 1971.

OYSTER, C. W. The human eye: structure and function. University of Alabama, Birmingham, Sinauer Associates, 1999.

PORTAL SÃO FRANCISCO. Campos Visuais. 2012. Disponível em: <www. portalsaofrancisco.com.br/alfa/corpo-humano-sistema-sensorial/visao-8.php $>$. Acesso em 23 fev. 2012.

POSNER, M. I. Chronometric exploration of mind. Hillsdale, New Jersey: Lawrence Erlbaum Associates, 1978.

POSNER, M. I. Orienting of Attention. Quaterly Journal of Experimental Pshychology, v. 32, p. 3-25, 1980.

POSNER, M. I.; COHEN, Y. Components of visual attention. In: BOUMA, H.; BOUWHUIS, G. G. (Ed.). Attention and Performance X. New Jersey: Eribaun, 1984. p. 531-556.

POSNER, M. I. E.; RAICHLE, M. Images of mind. Scientific American Library, 1994.

PSYCHOPY.Org [Internet]. Psychology software in Python. Version 1.75.01. Available from: < http://www.psychopy.org/>

REIS, V. P. Estudo da distribuição da atenção visuo-espacial em escolares. 2010. $93 \mathrm{f}$. Dissertação (Doutorado em Psicologia) - Instituto de Psicologia, Universidade de São Paulo, São Paulo, 2010. 
VAGHETTI, C. A. O.; ROESLER, H.; ANDRADE, A. Tempo de reação simples auditivo e visual em surfistas com diferentes níveis de habilidade: comparação entre atletas profissionais, amadores e praticantes. Revista Brasileira de Medicina Esporte, v. 13, n. 2, p. 81-85, 2007.

WILLIAMS, A. M. Perceptual skill in soccer: implication for talent identification and development. Journal of Sports Sciences, v. 18, p. 737-750, 2000.

WRIGHT, R. D.; LAWRENCE, M. W. Orienting of attention. Oxford University Press, Inc, 2008.

YAMAMOTO, J. K. An alternative measure of the reliability of ordinary kriging estimates. Math Geology, v. 32, p. 489-509, 2000. 


\section{ANEXO A - Termo de Consentimento Livre e Esclarecido}

\section{TERMO DE CONSENTIMENTO LIVRE E ESCLARECIDO}

ESTUDO: Mapeamento Espacial da Atenção Visual Mobilizada Voluntariamente em Atletas Você está sendo convidado (a) a participar do Projeto de Pesquisa acima citado. O documento abaixo contém todas as informações necessárias sobre a pesquisa que estamos desenvolvendo. Sua colaboração neste estudo será de muita importância para nós, mas se desistir a qualquer momento isso não causará nenhum prejuízo a você.

Eu, profissão portador da

Residente e domiciliado na inscrito no CPF

Cédula de Identidade (RG) nascido(a) em ..../........., abaixo assinado (a), concordo de livre e espontânea vontade em participar
como voluntário(a) do estudo "Mapeamento Espacial da Atenção Visual Mobilizada Voluntariamente em Atletas". Declaro que obtive todas as informações necessárias, bem como todos os eventuais esclarecimentos quanto às dúvidas por mim apresentadas.

\section{Estou ciente que:}

I) A participação neste projeto não tem objetivo de me submeter a um tratamento, bem como não me acarretará qualquer despesa com relação aos procedimentos técnicos efetuados no estudo;

II) Serão feito 5 experimentos com duração aproximada de 30 minutos no total;

III) Tenha a liberdade de desistir ou de interromper a colaboração neste estudo no momento em que desejar, sem a necessidade de qualquer explicação;

IV) Os resultados obtidos durante este ensaio serão mantidos em sigilo, mas concordo que sejam divulgados em publicações científicas, desde que meus dados pessoais não sejam mencionados;

V) Caso eu desejar, poderei pessoalmente tomar conhecimento dos resultados ao final desta pesquisa:

( ) Desejo conhecer os resultados desta pesquisa

( ) Não desejo conhecer os resultados desta pesquisa

VI) Concordo que o material poderá ser utilizado em outros Projetos desde que autorizado pela Comissão de Ética deste Instituto e pelo responsável por esta pesquisa

( ) Sim ou ( ) Não

São Paulo, .......de de 2012

Assinatura do Voluntário:

Testemunha 1:

Testemunha 2:

Nome/RG/Telefone

Nome/RG/Telefone

Responsável pelo Projeto: Marilia Martino de Sant'Ana/Bacharel em Esporte e Mestranda em Fisiologia Humana - Telefone: 3091-7236 


\section{ANEXO B - Entrevista Introdutória à Participação no Estudo \\ ENTREVISTA INTRODUTÓRIA À PARTICIPAÇÃO NO ESTUDO: \\ Mapeamento Espacial da Atenção Visual Mobilizada Voluntariamente em Atletas}

NOME:

ENDEREÇO:

CIDADE: ESTADO: TEL:

DATA DE NASC:

Apresenta algum problema de visão? ( ) SIM ( ) NÃO

Se SIM - qual o problema e quando começou?

Se NÃO - Há alguém na família que apresente? Qual o problema?

Faz algum tratamento/ usa óculos?

Histórico Desportivo:

Pratica regularmente uma ou mais atividades esportivas? $\quad(\quad) \operatorname{SIM} \quad(\quad$ ) NÃO

Se SIM

- Qual ou quais?

- Há quanto tempo?

- Participa de Campeonatos? Quais?

Se NÃO

- Já praticou alguma atividade esportiva? ( ) SIM ( ) NÃO

- Se sim, qual ou quais?

- Há quanto tempo não pratica atividades esportivas?

Avaliações complementares (preenchimento do pesquisador responsável)

Olho Dominante

Mão Dominante

( ) DIREITO
( ) DIREITA

) ESQUERDO

( ) ESQUERDA

Declaro que fui informado dos objetivos do presente estudo, ter consentido com a minha participação e haver preenchido o Termo de Consentimento Livre e Esclarecido em anexo.

São Paulo, de de 2012

Assinatura do Voluntário:

Assinatura do Pesquisador Responsável: 


\section{ANEXO C - Inventário de dominância lateral de Edimburgo (OLDFIELDS, 1971) \\ INVENTÁRIO DE DOMINÂNCIA LATERAL DE EDIMBURGO (OLDFIELDS, 1971)}

Por favor, indique sua preferência no uso das mãos nas seguintes atividades, pela colocação do sinal + na coluna apropriada. Onde a preferência é tão forte que você nunca usaria a outra mão, a menos que fosse forçado a usá-la, coloque ++ . Se em algum caso a mão utilizada é realmente indiferente, coloque + em ambas as colunas.

Algumas atividades requerem ambas as mãos. Nestes casos a parte da tarefa ou objeto para qual a preferência manual é desejada é indicada entre parênteses.

Por favor, tente responder a todas as questões, e somente deixe em branco se você não tiver qualquer experiência com o objeto ou tarefa.

\begin{tabular}{|l|l|l|l|}
\hline \multicolumn{2}{|l|}{} & Esquerda & Direita \\
\hline 1 & Escrever & & \\
\hline 2 & Desenhar & & \\
\hline 3 & Arremessar & & \\
\hline 4 & Uso de tesouras & & \\
\hline 5 & Escovar os dentes & & \\
\hline 6 & Uso de faca (sem garfo) & & \\
\hline 7 & Uso de colher & & \\
\hline 8 & Uso de vassoura (mão superior) & \\
\hline 9 & Acender um fósforo (mão do fósforo) & & \\
\hline 10 & Abrir uma caixa (mão da tampa) & & \\
\hline
\end{tabular}

São Paulo, de de 2012.

Nome do Voluntário:

Assinatura do Voluntário:

Assinatura do Pesquisador: 


\section{ANEXO D - Instruções - Experimento I (atenção difusa)}

\section{TELA DE INÍCIO DO TREINAMENTO}

Bom Dia!

Esse é um experimento de Tempo de Reação

Você verá sempre uma cruz de fixação (+) no centro da tela na qual você deve SEMPRE fixar o seu olhar. Estímulos (·) podem aparecer em qualquer ponto da tela do computador Sua tarefa consiste em apertar o botão do joystick O MAIS RÁPIDO POSSÍVEL quando aparecer o estímulo(·), mantendo o seu olhar SEMPRE na cruz de fixação (+) Aperte o botão para fazer um treinamento antes de começar

\section{TELA DE INÍCIO DO EXPERIMENTO}

OK, pronto para iniciar o experimento?

Lembre-se:

Esse é um experimento de Tempo de Reação

Você verá sempre uma cruz de fixação (+) no centro da tela na qual você deve SEMPRE fixar o seu olha. Estímulos $(\cdot)$ podem aparecer em qualquer ponto da tela do computador

Sua tarefa consiste em apertar o botão do joystick O MAIS RÁPIDO POSSÍVEL quando aparecer o estímulo(·), mantendo o seu olhar SEMPRE na cruz de fixação (+)

Aperte o botão para começar o experimento 


\section{ANEXO E- Instruções - Experimento II (Atenção Manifesta)}

\section{TELA DE INÍCIO DO TREINAMENTO}

Bom Dia!

Esse é um experimento de Tempo de Reação

Você verá sempre uma cruz de fixação (+) no centro da tela na qual você deve sempre fixar o seu olhar . Estímulos (·) aparecerão com maior probabilidade na região delimitada pela moldura, no centro da tela do computador

Sua tarefa consiste em apertar o botão do joystick O MAIS RÁPIDO POSSÍVEL quando aparecer o estímulo(·), mantendo o seu olhar SEMPRE na cruz de fixação (+)

Aperte o botão para fazer um treinamento antes de começar o experimento de verdade.

\section{TELA DE INÍCIO DO EXPERIMENTO}

Lembre-se:

Esse é um experimento de Tempo de Reação

Você verá sempre uma cruz de fixação (+) no centro da tela, na qual você deve sempre fixar o seu olhar. Estímulos $(\cdot)$ aparecerão com maior probabilidade na região delimitada pela moldura, no centro da tela do computador

Sua tarefa consiste em apertar o botão do joystick O MAIS RÁPIDO POSSÍVEL quando aparecer o estímulo(·), mantendo o seu olhar SEMPRE na cruz de fixação (+)

Aperte o botão para começar o experimento 


\section{ANEXO F - Instruções - Experimento III (Atenção Encoberta Esquerda)}

\section{TELA DE ÍNICIO DO TREINAMENTO}

Bom Dia!

Esse é um experimento de Tempo de Reação

Você verá sempre uma cruz de fixação (+) no centro da tela, na qual você deve sempre fixar o seu olhar. Estímulos (·) aparecerão com maior probabilidade na região delimitada pela moldura, localizada a esquerda da cruz de fixação

Sua tarefa consiste em apertar o botão do joystick O MAIS RÁPIDO POSSÍVEL quando aparecer o estímulo(·), mantendo o seu olhar SEMPRE na cruz de fixação (+)

Aperte o botão para fazer um treinamento antes de começar o experimento de verdade.

\section{TELA DE INÍCIO DO EXPERIMENTO}

OK, pronto para iniciar o experimento?

Lembre-se:

Esse é um experimento de Tempo de Reação

Você verá sempre uma cruz de fixação (+) no centro da tela, na qual você deve sempre fixar o seu olhar. Estímulos (·) aparecerão com maior probabilidade na região delimitada pela moldura, localizada a esquerda da cruz de fixação

Sua tarefa consiste em apertar o botão do joystick O MAIS RÁPIDO POSSÍVEL quando aparecer o estímulo(·), mantendo o seu olhar SEMPRE na cruz de fixação (+)

Aperte o botão para começar o experimento 


\section{ANEXO G - Instruções - Experimento IV (Atenção Encoberta Direita)}

\section{TELA DE INÍCIO DO TREINAMENTO}

Bom Dia!

Esse é um experimento de Tempo de Reação

Você verá sempre uma cruz de fixação (+) no centro da tela na qual você deve sempre fixar o seu olhar. Estímulos (·) aparecerão com maior probabilidade na região delimitada pela moldura, localizada a direita da cruz de fixação

Sua tarefa consiste em apertar o botão do joystick O MAIS RÁPIDO POSSÍVEL quando aparecer o estímulo(·), mantendo o seu olhar SEMPRE na cruz de fixação (+)

Aperte o botão para fazer um treinamento antes de começar o experimento de verdade.

\section{TELA DE INÍCIO DO EXPERIMENTO}

OK, pronto para iniciar o experimento?

Lembre-se:

Esse é um experimento de Tempo de Reação

Você verá sempre uma cruz de fixação (+) no centro da tela na qual você deve sempre fixar o seu olhar. Estímulos (·) aparecerão com maior probabilidade na região delimitada pela moldura, localizada a direita da cruz de fixação

Sua tarefa consiste em apertar o botão do joystick O MAIS RÁPIDO POSSÍVEL quando aparecer o estímulo(·), mantendo o seu olhar SEMPRE na cruz de fixação (+)

Aperte o botão para começar o experimento 


\section{ANEXO H - Instruções - Experimento V (Atenção Dividida)}

\section{TELA DE ÍNICIO DO TREINAMENTO}

Bom Dia!

Esse é um experimento de Tempo de Reação

Você verá sempre uma cruz de fixação (+) no centro da tela na qual você deve sempre fixar o seu olhar. Estímulos (·) aparecerão com maior probabilidade nas regiões delimitadas pelas molduras, localizadas a esquerda e a direita da cruz de fixação

Sua tarefa consiste em apertar o botão do joystick O MAIS RÁPIDO POSSÍVEL quando aparecer o estímulo(·), mantendo o seu olhar SEMPRE na cruz de fixação (+)

Aperte o botão para fazer um treinamento antes de começar o experimento de verdade.

\section{TELA DE INÍCIO DO EXPERIMENTO}

OK, pronto para iniciar o experimento?

Lembre-se:

Esse é um experimento de Tempo de Reação

Você verá sempre uma cruz de fixação (+) no centro da tela na qual você deve sempre fixar o seu olhar. Estímulos (·) aparecerão com maior probabilidade nas regiões delimitadas pelas molduras, localizadas a esquerda e a direita da cruz de fixação

Sua tarefa consiste em apertar o botão do joystick O MAIS RÁPIDO POSSíVEL quando aparecer o estímulo(·), mantendo o seu olhar SEMPRE na cruz de fixação (+)

Aperte o botão para começar o experimento 


\section{ANEXO I - Intervalo Entre Os Blocos, Em Todos Os Experimentos}

Aguarde 5 segundos para recomeçar o teste.

Lembre-se de manter o seu olhar SEMPRE na cruz de fixação (+)

\section{PAUSA ENTRE OS BLOCOS}

Essa é uma pausa. Aguarde o tempo que desejar.

Pressione o botão para continuar com o experimento.

Lembre-se de manter o seu olhar SEMPRE na cruz de fixação (+) 